Article

\title{
Drone Launched Short Range Rockets
}

\author{
Mikhail V. ShuboviD \\ Department of Civil and Environmental Engineering, University of MA Lowell, One University Ave, \\ Lowell, MA 01854,USA; viktor_shubov@uml.edu
}

Received: 16 February 2020; Accepted: 26 May 2020; Published: 8 June 2020

check for updates

\begin{abstract}
A concept of drone launched short range rockets (DLSRR) is presented. A drone or an aircraft rises DLSRR to a release altitude of up to $20 \mathrm{~km}$. At the release altitude, the drone or an aircraft is moving at a velocity of up to $700 \mathrm{~m} / \mathrm{s}$ and a steep angle of up to $68^{\circ}$ to the horizontal. After DLSRRs are released, their motors start firing. DLSRRs use slow burning motors to gain altitude and velocity. At the apogee of their flight, DLSRRs release projectiles which fly to the target and strike it at high impact velocity. The projectiles reach a target at ranges of up to $442 \mathrm{~km}$ and impact velocities up to $1.88 \mathrm{~km} / \mathrm{s}$. We show that a rocket launched at high altitude and high initial velocity does not need expensive thermal protection to survive ascent. Delivery of munitions to target by DLSRRs should be much less expensive than delivery by a conventional rocket. Even though delivery of munitions by bomber aircraft is even less expensive, a bomber needs to fly close to the target, while a DLSRR carrier releases the rockets from a distance of at least $200 \mathrm{~km}$ from the target. All parameters of DLSRRs, and their trajectories are calculated based on theoretical (mechanical and thermodynamical) analysis and on several MatLab programs.
\end{abstract}

Keywords: reusable first stage; short range ballistic missiles; rocket artillery; drone launched rockets

\section{Introduction}

In this work, we discuss a possibility of a short range rocket launched from a fighter or a drone. The carrier aircraft or drone is called Rocket Launcher Aircraft (RLA). RLA can either be a modified fighter like F16, or an aircraft or drone constructed specifically for a rocket-launching mission. The rocket or rockets are called Drone Launched Short Range Rockets (DLSRR). In this work, we present the models and calculate performance of DLSRR, but not RLA. The author plans to write another work on RLA.

RLA raises DLSRRs to an altitude of $12 \mathrm{~km}-20 \mathrm{~km}$ and fires them. At the firing point, RLA and hence DLSRRs have a velocity of $500 \mathrm{~m} / \mathrm{s}-700 \mathrm{~m} / \mathrm{s}$ in the ground system of coordinates. Their motion is at an angle of $53^{\circ}$ to $68^{\circ}$ with respect to the horizontal. DLSRR has a slow-burning motor which burns $60 \mathrm{~s}-80 \mathrm{~s}$. After the DLSRR motor burns out, it follows a ballistic trajectory. As the DLSRR reaches the apogee of $77 \mathrm{~km}-111 \mathrm{~km}$, it releases one or more warheads which fly to the target. The DLSRR itself lands a few km away from the target.

Very little work has been done on military rockets with reusable first stage. Between 2010 and 2012, US Air Force had a project called "Reusable Booster System" to assist long-range rockets [1]. Jeffery Becker's concept is Theater Guided Missile Carrier (T-CVG), which is similar to our RLA. In Becker's concept, a modified version of reusable first stage of Falcon I rocket is used as RLA. This stage rises almost vertically, firing the second stage rockets which have a range of $1600 \mathrm{~km}$ to $8000 \mathrm{~km}$ [2]. Our proposal is more modest. It is likely that multiple forms of military rocket systems with reusable first stage will exist.

Delivery of payload to target should be less expensive than conventional short range rocket systems. It may be noticed that conventional fighters and bombers also deliver munitions to a 
relatively long distance at a relatively low price. Unlike RLA, conventional fighters and bombers expose themselves to antiaircraft fire, which may make their operations inefficient. RLA never flies into hostile territory.

The current work consists of six Sections. In Section 2, we describe the state-of-the-art technology for long range precision strikes. In Section 2.1, we describe the state-of-the-art rocket systems capable of making precise strikes to the range of $80 \mathrm{~km}$ to $600 \mathrm{~km}$ also mentioning some longer range missiles. In Tables 1 and 2, we present the cost of delivery per $\mathrm{kg}$ of payload. For ranges of $156 \mathrm{~km}$ to $600 \mathrm{~km}$, the costs are from $\$ 2700$ per $\mathrm{kg}$ to $\$ 6700$ per $\mathrm{kg}$ depending on the missile. Thus, we establish the need for a less expensive system. In Section 2.2, we describe historic and state of art guided munitions. In Section 2.3, we describe some antiaircraft missiles. The main reason the RLA-DLSRR system has not been developed so far is because the bomber aircraft had the capability of a long-range precision strike. The new generation of anti-aircraft missiles may make bombers obsolete in any sizable confrontation.

In Section 3, we introduce the physics of rocket flight. We present the equations describing the rocket trajectory. We also introduce the concepts of Specific Impulse, gravity loss, and drag loss. These concepts are important for rocket development. The material in Section 3 is used to write programs and perform calculations with results presented in subsequent sections:

In Section 4, we discuss solid propellant rockets. In Section 4.1, we describe the rockets we need for DLSRRs In Section 4.2, we present properties of several fuel compositions. In Section 4.3, we discuss possible fuel grain shapes. We also discuss different rocket container materials along with their corresponding advantages and disadvantages.

In Section 5, we calculate rocket and warhead performance. In Section 5.1, we describe the performance of DLSRRs fired from RLA. Ranges obtained for these rockets are $263 \mathrm{~km}$ to $442 \mathrm{~km}$ depending on launch conditions and propellant burning time. In Section 5.2, we calculate the impact velocity of several projectiles. The Hypervelocity Projectile is described in Section 5.2.1. Europrojectile is a small tungsten projectile described in Section 5.2.2. Europrojectile has the best performance.

Fired from $12 \mathrm{~km}$ altitude with an initial velocity of $500 \mathrm{~m} / \mathrm{s}$, and rocket burning time of $80 \mathrm{~s}$, DLSRR has a range of $264 \mathrm{~km}$. In this case, the impact velocity of the Europrojectile is $1400 \mathrm{~m} / \mathrm{s}$. Fired from $16 \mathrm{~km}$ altitude with an initial velocity of $600 \mathrm{~m} / \mathrm{s}$, and rocket burning time of $50 \mathrm{~s}$, DLSRR has a range of $361 \mathrm{~km}$. In this case, the impact velocity of the Europrojectile is $1675 \mathrm{~m} / \mathrm{s}$. Fired from $20 \mathrm{~km}$ altitude with an initial velocity of $700 \mathrm{~m} / \mathrm{s}$, and rocket burning time of $30 \mathrm{~s}$, DLSRR has a range of $442 \mathrm{~km}$. In this case, the impact velocity of the Europrojectile is $1879 \mathrm{~m} / \mathrm{s}$. High release altitude, high release velocity, and short propellant burning times enhance rocket range and warhead impact velocity. Higher release altitude and velocity place greater requirement on RLA, thus making the launch of each DLSRR more expensive.

In Section 6, we describe the aerodynamic heating and thermal protection. In Section 6.1, we present the general expressions for aerodynamic heating of different parts of the rocket. In Section 6.1.1, we present the equations for the stagnation point heat flux. In Section 6.1.2, we present the equations for general turbulent flow heat flux. In Section 6.1.3, we present the equations for the heat flux on rocket cylinder. In Section 6.1.4, we present the equations for the nose cone heat flux. The material in Section 6.1 is used to write programs and perform calculations with the results presented in Section 6.3. In Section 6.2, we discuss the heat shields. In Section 6.2.1, we describe radiation heat shields. In Section 6.2.2, we describe heat sink shields. In Section 6.3, we calculate the heating rates and temperatures of different parts of DLSRR during flight. In Section 6.3.1, we calculate stagnation point temperature as a function of time. The temperature never exceeds $1200{ }^{\circ} \mathrm{C}$-well within the capability of thermal protection. In Section 6.3.2, we calculate temperatures of several points on the nose cone as a function of time. The temperature never exceeds $960{ }^{\circ} \mathrm{C}$. In Section 6.3.2, we calculate temperature DLSRR cylinder base as a function of time. The cylinder base temperature never exceeds $94{ }^{\circ} \mathrm{C}$-at this temperature, aluminum does not soften.

In Section 7, we present a conclusion. In Appendix A, we describe the MatLab programs we have written and used in this work. 


\section{Artillery Rockets and Warheads}

\subsection{Artillery Rockets}

Short range ballistic missiles can make precise strikes at ranges from $150 \mathrm{~km}$ to $1000 \mathrm{~km}$. Some of the modern systems are extremely expensive. As we see from Tables 1 and 2, the cost per $1 \mathrm{~kg}$ of munitions delivered to the target varies between $\$ 1500$ and $\$ 6500$ depending on the range.

Scud missile was the original Soviet short range ballistic missile. Scud-A introduced in 1957 delivered a $950 \mathrm{~kg}$ payload to a range of $180 \mathrm{~km}$. Scud-B introduced in 1964 delivered a $985 \mathrm{~kg}$ payload to a range of $300 \mathrm{~km}$. Over 7000, Scud-B missiles have been built. Scud-C introduced in 1965 delivered a $600 \mathrm{~kg}$ payload to a range of $600 \mathrm{~km}$. Scud-D introduced in 1989 delivered a $985 \mathrm{~kg}$ payload to a range of $700 \mathrm{~km}$. Scud missiles have been used extensively in Iran-Iraq War. Between October 1988 and February 1992, approximately 1700 to 2000 Scud missiles were launched in Afghanistan's civil war [3]. Original Scud missiles had poor guidance, but in modern times, relatively inexpensive and precise guidance systems are available. Russian short range rocket Iskander delivers a $480 \mathrm{~kg}$ payload to a distance of $500 \mathrm{~km}$ or a $700 \mathrm{~kg}$ unit to a distance of $400 \mathrm{~km}$. The missile has very precise guidance. Russia has only 136 such missiles. The price is kept secret but should be at least $\$ 4$ Million per unit [4] (p. 125).

American short range rocket ATACMS delivers a $230 \mathrm{~kg}$ payload to $300 \mathrm{~km}$ or a $560 \mathrm{~kg}$ payload to $165 \mathrm{~km}$. The missile has very precise guidance. USA has 3700 units [5]. The unit cost of ATACMS is \$1.5 Million [6] (p. 19). Israel has developed LORA ("Long Range Attack") missile, which delivers a $570 \mathrm{~kg}$ payload to a distance of $400 \mathrm{~km}$. The missile has very precise guidance. The unit cost is not disclosed [7].

China has Dong-Feng ballistic missiles. Some of these missiles are intercontinental ballistic missiles. Main short-range ballistic missiles are DF-11 and DF-15. DF-11 launches an $800 \mathrm{~kg}$ payload to a range of $280 \mathrm{~km}$ or a $500 \mathrm{~kg}$ payload to a range of $350 \mathrm{~km}$. DF-11A launches a $500 \mathrm{~kg}$ payload to a range of $350 \mathrm{~km}$. DF-15 launches a $500 \mathrm{~kg}$ payload to a range of $600 \mathrm{~km}$. DF-15A launches a $600 \mathrm{~kg}$ payload to a range of $600 \mathrm{~km}$. DF-15B launches a $600 \mathrm{~kg}$ payload to a range of $700 \mathrm{~km} \mathrm{[8]} \mathrm{(p.} \mathrm{48).} \mathrm{China}$ possesses about 1200 ballistic rockets with ranges of $300 \mathrm{~km}$ to $1000 \mathrm{~km}$ [9] (p. 31).

Artillery rockets can deliver guided submunitions much better than artillery projectiles, since they are not subject to extreme accelerations. Guided Multiple Launch Rocket System (GMLRS) is used by the USA. M30 and M31 rockets deliver a $90 \mathrm{~kg}$ payload to $84 \mathrm{~km}$. The missile has very precise guidance [10] (p. 112). By 2014, 19,942 GMLRS rockets have been procured at a cost of $\$ 125,850$ per rocket. During the years 2014-2015, 2940 GMLRS rockets have been procured at a cost of $\$ 400$ Million [6] (p. 19)—which gives a GMLRS rocket a unit price of $\$ 136,000$. Smerch is a powerful Russian rocket artillery system. A single vehicle carries 12 rockets. A single rocket delivers a $243 \mathrm{~kg}$ warhead to a range of $90 \mathrm{~km}$ with great accuracy. Multiple Launch Rocket System (MLRS) Smerch has been used in Second Chechen War, War in Donbass, and Syrian Civil War. The unit price is undisclosed [11]. China has several powerful rocket artillery systems. AR3 is a $370 \mathrm{~mm}$ caliber rocket which delivers a $200 \mathrm{~kg}$ warhead to a range of $220 \mathrm{~km}$ with great accuracy. Each launcher has eight rockets [12].

USA did use the rockets described above in recent local conflicts. Out of 17,184 GMLRS Unitary rockets produced, 3141 have been used in Iraq and Afghanistan. Out of 1650 Army Tactical Missile System (ATACMS) Block I rockets produced, 32 have been used in Desert Storm and 379 in Operation Iraqi Freedom. Out of 610 ATACMS Block IA rockets produced, 74 have been used in Operation Iraqi Freedom. Out of 176 ATACMS Quick Reaction Unitary rockets produced, 16 have been used in Operation Iraqi Freedom and 42 in Operation Enduring Freedom. Out of 513 ATACMS 2000 rockets produced, 33 have been used in Operation Enduring Freedom [13].

The measure of expense for a missile system at a given range is the cost per unit delivered weight. Below, we tabulate the costs for the few solid propellant rockets for which the information is not classified. 
Table 1. Solid propellant missiles.

\begin{tabular}{ccccc}
\hline Missile & Range & Throw Weight & Unit Cost & Cost per kg Delivered \\
\hline GMLRS & $84 \mathrm{~km}$ & $90 \mathrm{~kg}$ & $\$ 136,000$ & $\$ 1500$ \\
ATACMS & $165 \mathrm{~km}$ & $560 \mathrm{~kg}$ & $\$ 1,500,000$ & $\$ 2700$ \\
ATACMS & $300 \mathrm{~km}$ & $230 \mathrm{~kg}$ & $\$ 1,500,000$ & $\$ 6500$ \\
Trident II [14] & $7840 \mathrm{~km}$ & $2800 \mathrm{~kg}$ & $\$ 37,300,000$ & $\$ 13,300$ \\
\hline
\end{tabular}

Liquid propellant rockets are less expensive, but they require about an hour to be prepared for firing. Some of them are listed in Table 2 below. The first two prices in 1990s are given in [15]. The prices listed below are twice the amount of old prices.

Table 2. Liquid propellant missiles.

\begin{tabular}{ccccc}
\hline Missile & Range & Throw Weight & Unit Cost & Cost per kg Delivered \\
\hline Dong-Feng 15 & $500 \mathrm{~km}$ & $600 \mathrm{~kg}$ & $\$ 4,000,000$ & $\$ 6700$ \\
Scud C & $600 \mathrm{~km}$ & $600 \mathrm{~kg}$ & $\$ 2,000,000$ & $\$ 3300$ \\
Agni II [16] & $2000 \mathrm{~km}$ & $1000 \mathrm{~kg}$ & $\$ 5,100,000$ & $\$ 5100$ \\
\hline
\end{tabular}

As can be seen from the above table, the cost of delivering munitions by short range ballistic missiles is very high. The costs of long range missiles are relatively low for their range.

\subsection{Guided Munitions}

One of the most important factors enabling long-range missiles and artillery is appearance and development of guided munitions. Precise guidance allows projectiles to strike targets tens or hundreds kilometers away with an accuracy of a few meters.

The most common guided munition is the air bomb. Guided bombs and glide bombs were first used by Germany in 1943 [17] (p. 4). Since that time, relatively inexpensive guided bombs came into common use-during operations, Enduring Freedom in 2001 and Iraqi Freedom in 2003, over 50\% of all bombs used were guided [17] (p. 20). Joint Direct Attack Munition (JDAM) is a guidance kit which can be attached to any unguided bomb in order to transfer it into a guided bomb [17] (p. 213). "Through FY 2005, 105,286 JDAM kits had been procured for an average unit-procurement cost of $\$ 21,379$ each" [17] (p. 217). Recently, the Boeing corporation has produced 300,000th JDAM [18]. Warheads used by the system we are proposing in this paper are similar to bombs dropped from an apogee of the second-stage rocket flight. They are much lighter than conventional bombs, but they will experience strong heating due to high velocity.

Guided projectiles and projectile guidance kits are much more hardy than bomb or missile guidance - they must survive acceleration of thousands of g's inside a cannon. Low cost guidance systems for cannon launched projectiles are becoming available [19]. The present generation of guided tube artillery munitions uses precision guidance kits attached to non-guided projectiles. The kit currently used by US Army is "M1156 Precision Guidance Kit (PGK)". PGK consists of a fuse placed in the nose of a non-guided projectile. M1156 uses GPS guidance. The projectile equipped with a fuse was suppose to have a circular error probability (CEP) of $30 \mathrm{~m}$ [20] (p. 21). Almost always new technology performs below expected parameters with M1156 being a nice exception. "During its first lot acceptance testing in April 2015, the M1156 demonstrated median accuracy of less than $10 \mathrm{~m}$ with a reliability of $97 \%$ when fired from the $155 \mathrm{~mm} / 39$-calibre M109A6 Paladin." [21] (p. 8). A German test had even better results. "From a distance of $27 \mathrm{~km}, 90$ percent of the PGK-equipped German shells landed within $5 \mathrm{~m}$ of the target" [22]. PGK M1156 have a unit price of $\$ 10,000$ [23].

In 2013, 1300 PGKs have been delivered to US Armed Forces in Afghanistan. Australia has a contract with USA for 4000 PGKs [20] (p. 21). By May 2018, 25,000 units have been produced [24]. One of the main advantages of M1156 is its simplicity. Indeed, see Figure 1. 
The kit has a single moving part, the canard assembly, which can only rotate along the longitudinal axis, the wings having a fixed cant; two couples of opposite wings have the same direction and thus provide lift, while the two despin wings provide counter-rotation [20] (p. 21).

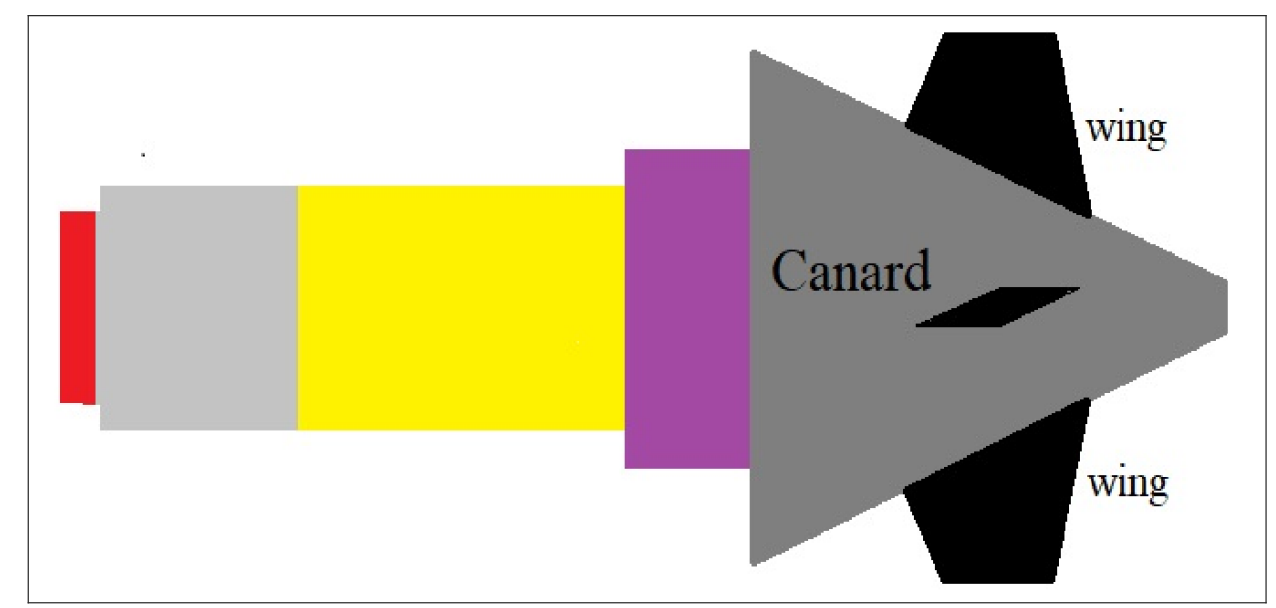

Figure 1. Projectile guidance kit.

In addition, 100,000 PGKs are ordered [21] (p. 8). Israel is also developing a guidance kit called "Silver Bullet". The kit can be fitted to the nose of any conventional or rocket assisted projectile. This PGK does have four moving wings [20] (pp. 21-22). Another guidance kit developed by Israel is TopGun [25]. Guidance kits used to guide projectiles should be able to guide warheads released by second-stage rockets.

The Hypervelocity Projectile (HPV) has been produced and tested. It is likely the next generation of guided munitions [26] (p. 12). Its guidance should easily survive extreme acceleration within a launcher and heating within atmosphere. The projectile's guidance system should work even if it is shot from an electromagnetic cannon to a range of $400 \mathrm{~km}$. HPV has a conical shape. It is made mostly out of tungsten. HPV's weight is $11.4 \mathrm{~kg}$, length $64.2 \mathrm{~cm}$, and caliber $7.83 \mathrm{~cm}$. It is shown in Figure 2 below.

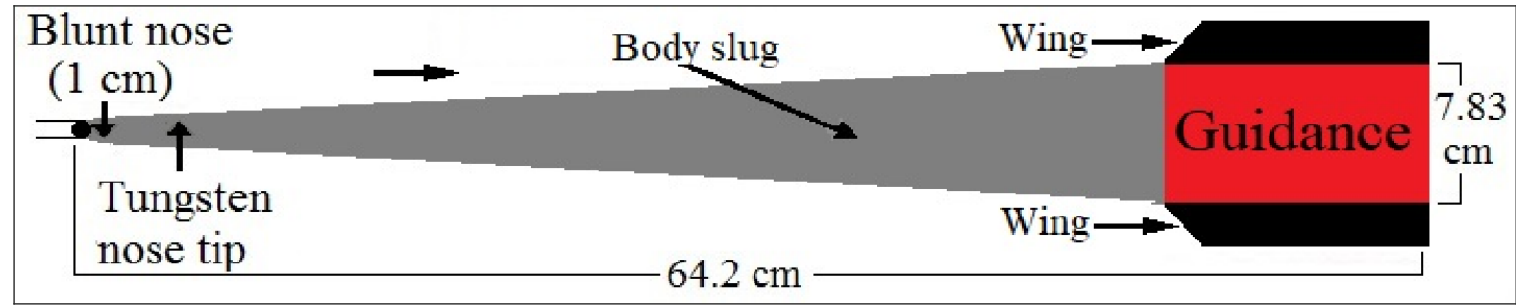

Figure 2. Hypervelocity projectile .

HPV is very fit to be one of possible warheads carried by a drone launched short range rocket.

\subsection{Anti-Aircraft Missiles}

One of the main reasons the DLSRR technology has not been developed this far is that technology for precision strike at a long range existed for many decades. As we have discussed in Section 2.2, bomber aircraft made it possible to bring guided munition to the target at a relatively low cost. Thus, there was no need for any unconventional delivery system.

In large-scale modern warfare, bomber aircraft may become a lost technology due to proliferation of very powerful anti-aircraft missiles. The main Russian surface to air missile in 2020 is S400. S400 missile with GRAU index 40N6 has a range of $400 \mathrm{~km}$, ceiling of $185 \mathrm{~km}$, and maximum velocity 
$2000 \mathrm{~m} / \mathrm{s}$. The unit cost of the missile is $\$ 3.6$ Million [27]. A new SAM called S500 should exceed the capabilities of S400. A new generation of SAMs may also employ Multiple Kill Vehicle (MKV). One rocket releases several guided submunitions each of which is capable of destroying the targeted aircraft [28] (p. 42).

The USA also has very powerful antiaircraft missiles. SM3 Block 1B missile can destroy any aircraft or an incoming missile within $700 \mathrm{~km}$. The warhead weighs $29 \mathrm{~kg}$. The missile costs $\$ 12$ million in 2018 dollars [29]. SM6 missile can destroy any aircraft within $300 \mathrm{~km}$, it has a $64 \mathrm{~kg}$ warhead and a price tag of $\$ 4$ million in 2018 dollars [30].

These missiles would make it impossible for any conventional bomber to operate in any sizable conflict. RLA does not approach the target closer then about $200 \mathrm{~km}$. Moreover, it is possible to design an RLA which stays in the air only for a short period of time not exceeding $10 \mathrm{~min}$.

\section{The Physics of Rocket Flight}

Consider a rocket that starts its ascent at an altitude $h_{0}$, which is generally $12 \mathrm{~km}$ to $20 \mathrm{~km}$, with the initial speed being $v_{0}$, which is generally $500 \mathrm{~m} / \mathrm{s}$ to $700 \mathrm{~m} / \mathrm{s}$, with the angle with respect to horizontal line $\alpha_{0}$, generally between $51^{\circ}$ and $68^{\circ}$.

Three forces acting on a rocket during flight are presented in Figure 3. The gravitational force is $M(t) \mathbf{g}$ pointed in $-\hat{y}$ direction. Notice that, while the rocket fuel is burning, the rocket mass is decreasing. The air resistance or drag force $\mathbf{F}_{d}$ is acting in the opposite direction of velocity. The magnitude of $F_{d}$ is

$$
\begin{aligned}
F_{d} & =C_{d}(\mathcal{M}) \frac{\rho v^{2} A}{2} \\
& =C_{d}(\mathcal{M}) \mathcal{M}^{2} \frac{\rho v_{s}^{2} A}{2}
\end{aligned}
$$

where $C_{d}(\mathcal{M})$ is the Mach-number dependent drag coefficient, $v$ is the velocity, $v_{s}$ is the speed of sound, $\mathcal{M}$ is the Mach number, i.e., $\mathcal{M}=v / v_{s}, \rho$ is the air density, and $A$ is the base area of the rocket. Let $M$ be the rocket mass. Then, thrust force $\mathbf{F}_{t}$ acting in the direction of velocity is given by

$$
F_{t}=\dot{M} v_{e}
$$

where $\dot{M}$ is the fuel burning rate, and $v_{e}$ is the equivalent exhaust velocity.

The exhaust velocity increases as the rocket rises out of dense atmospheric layers. For the DLSRR launched at a high altitude, $v_{e}$ barely changes. For some propellant grains, the fuel burning rate changes during the burn time. In our case, we assume an almost steady burning rate

$$
\dot{M}=\frac{M f_{p}}{t_{b}} \quad \text { for time } 0 \leq t \leq t_{b},
$$

where $t_{b}$ is the burn time and $f_{p}$ is the propellant mass fraction given by

$$
f_{p}=\frac{\text { Propellant mass }}{\left\{\begin{array}{l}
\text { Combined mass of propellant, } \\
\text { rocket, and payload }
\end{array}\right\}}
$$

Since we know the forces acting on the rocket, we calculate its trajectory via the MatLab programs FirstStage.m and Rocket.m, which are described in Appendix A. 


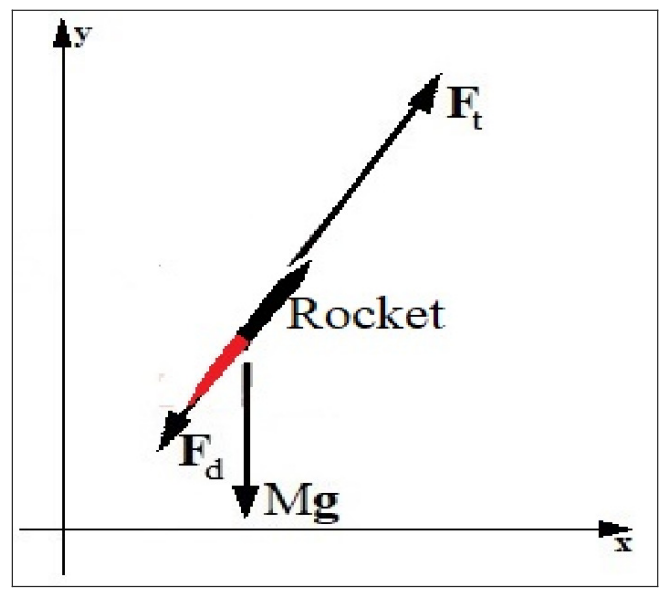

Figure 3. Forces acting on a firing rocket.

The change in velocity produced by the rocket engine is

$$
v_{r}=\int_{0}^{t_{b}} \frac{\mathbf{F}_{t}(t)}{M(t)} d t
$$

where $M(t)$ is the rocket mass at time $t$. According to Tsialkovski Rocket Equation [31],

$$
v_{r}=-\bar{v}_{e} \ln \left(1-f_{p}\right),
$$

where $\bar{v}_{e}$ is the average exhaust velocity. In our case, $\bar{v}_{e} \approx 2100 \mathrm{~m} / \mathrm{s}$. For expensive rockets with flame temperatures in excess of $2800^{\circ} \mathrm{C}, \bar{v}_{e} \approx 2600 \mathrm{~m} / \mathrm{s}$.

The drag loss is

$$
v_{d}=\int_{0}^{t_{0}} \frac{F_{d}(t)}{M(t)} d t,
$$

where $M(t)$ is the rocket mass at time $t, t_{0}$ is the time it takes the rocket to reach the apogee, and $F_{d}(t)$ is the drag force at the time moment $t$.

At this point, we define the effective loss of rocket velocity due to gravity. It is called gravitational loss and denoted $v_{g}$. We define this loss in terms of the rocket's speed and altitude at the apogee. First, assume that the rocket is given its impulse $v_{r}$ instantaneously, and the drag loss is negligible. Such assumption is an abstract limit for a rocket, but it may be reality for a projectile fired at high altitude. Then, the total kinetic and potential energy per unit rocket (projectile) mass at the beginning of trajectory is

$$
\mathcal{E}=g h_{0}+\frac{\left(v_{0}+v_{r}\right)^{2}}{2},
$$

where $h_{0}$ is the launch altitude, $v_{0}$ is the launch velocity, and $v_{r}$ is the velocity gain due to the action of the rocket engine. Second, we incorporate the aerodynamic drag loss into (8) to obtain

$$
\mathcal{E}=g h_{0}+\frac{\left(v_{0}+v_{r}-v_{d}\right)^{2}}{2},
$$

where $v_{d}$ is the drag loss. Third, we incorporate the gravitational loss into (9) to obtain

$$
\mathcal{E}=g h_{0}+\frac{\left(v_{0}+v_{r}-v_{d}-v_{g}\right)^{2}}{2},
$$

where $v_{g}$ is the gravitational loss. In the above expressions, $v_{0}, v_{r}, v_{d}$, and $h_{0}$ are known, while both $\mathcal{E}$ and $v_{g}$ are unknown. In order to calculate $v_{g}$, we calculate $\mathcal{E}$ using the parameters of rocket motion at 
the apogee. The maximum ascent of the rocket, or the height the rocket attains at apogee is denoted $h_{A}$. The rocket speed at the apogee is $v_{A}$. The vector of this speed is in the forward direction. The total kinetic and potential energy per unit rocket mass at the apogee is

$$
\mathcal{E}=g h_{A}+\frac{v_{A}^{2}}{2}
$$

which is the same as the rocket energy earlier in the path given in (10). Equating (10) and (11), we obtain

$$
v_{g}=\left(v_{0}+v_{r}\right)-v_{d}-\sqrt{2 g\left(h_{A}-h_{0}\right)+v_{A}^{2}} .
$$

\section{DLSRR Engines}

\subsection{Solid Propellant Rockets}

In the present and the two following sections, we consider a solid propellant rocket. It is schematically presented in Figure 4 below.

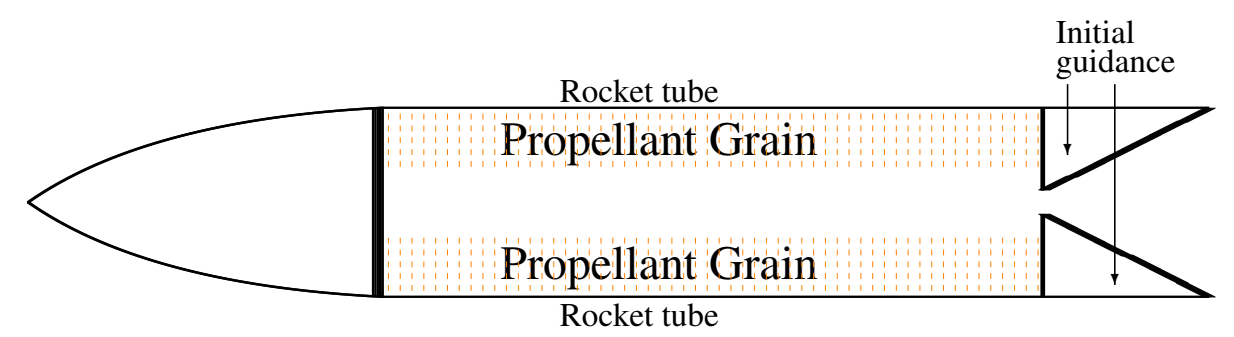

Figure 4. Solid propellant rocket.

The DLSRR should consist of a rocket with one or more guided warheads. These rockets would be much less expensive than conventional rockets with similar range and payload. First, the fact that the DLSRR starts at an altitude of over $12 \mathrm{~km}$ to $20 \mathrm{~km}$ with a velocity $500 \mathrm{~m} / \mathrm{s}$ to $700 \mathrm{~m} / \mathrm{s}$ would reduce $\Delta v$ needed for the rocket to achieve a given range by at least $750 \mathrm{~m} / \mathrm{s}$. The reduction in needed $\triangle v$ is greater than the initial velocity due to the fact that the rocket starts out at high altitude. First, it decreases the drag loss. Second, initial elevation itself reduces $\Delta v$ needed to achieve a given range. Second, as we show in the following sections, a rocket starting at high altitude with high initial velocity does not need to experience high firing acceleration. While most artillery rockets burn their fuel within 2-3 s, the DLSRR will be able to achieve good results even if it takes 40-60 s to burn its fuel. A solid-propellant rocket with slow burning fuel is much less expensive to manufacture. Third, slow-burning fuels have much lower flame temperature [32], which greatly reduces the cost of exhaust and initial guidance. There is a general pattern that propellants with higher combustion temperatures have higher burning rates than propellants with lower combustion temperatures at the same pressure. For example, ammonium nitrate propellants have low burning rates. Even though exceptions exist, they are rare. This phenomenon has a physical explanation. Lower temperature flames send lower heat flux back to the propellant. Lower heat flux causes the propellant to pyrolyze at lower rate. Thus, the overall regression and burning rate of the propellant is lower.

The initial guidance of DLSRR should be simple. It must make sure that DLSSR does not sway off the course by more than a kilometer. Probably inertial guidance with fins within the nozzle can accomplish the task.

\subsection{Propellant Composition}

Most modern artillery rockets as well as space rocket boosters use a solid propellant containing $70 \%$ ammonium perchlorate (AP), 15\% aluminum powder, and 15\% HTPB binder [33] (p. 479). Such propellant is expensive to manufacture due to the fact that AP is highly explosive. Other propellants 
contain high explosives and highly nitrated nitrocellulose. All of them are expensive and dangerous to handle. All the aforementioned propellants have flame temperatures of $2500{ }^{\circ} \mathrm{C}$ to $3500{ }^{\circ} \mathrm{C}$. Such exhaust temperatures require expensive nozzles.

DLSRR have a choice of fuels burning at lower temperature and rate. Some formulations contain ammonium nitrate (AN). The chemical formula for ammonium nitrate is $\mathrm{NH}_{4} \mathrm{NO}_{3}$. Its heat of formation is $367 \mathrm{~kJ} / \mathrm{mol}$. Ammonium Nitrate density is $1.725 \mathrm{~g} / \mathrm{cm}^{3}$ [34] (p. 256). Ammonium Nitrate undergoes phase transitions at $-18{ }^{\circ} \mathrm{C}$ and $+32{ }^{\circ} \mathrm{C}$. These phase transitions are accompanied by volume change of about $4 \%$, thus they must be avoided in order to avoid fuel grain destruction [34] (p. 263). Ammonium Nitrate can be phase-stabilized by addition of $10 \%$ potassium nitrate or $2 \%$ potassium fluoride [34] (pp. 267-268).

Other formulations have mildly nitrated nitrocellulose. The chemical formula for Nitrocellulose is $\mathrm{C}_{6} \mathrm{H}_{10-x} \mathrm{O}_{5}\left(\mathrm{NO}_{2}\right)_{x}$. Its atomic mass is $162+45 x$. Its binding energy is $(961.5-103.6 \cdot x) \mathrm{kJ} / \mathrm{mol}$. The number $0<x<3$ determines the oxidizer content of nitrocellulose. Nitroglycerin (NG) is used in double base propellants with nitrocellulose [35]. Nitroglycerin formula is $\mathrm{H}_{5} \mathrm{C}_{3} \mathrm{~N}_{3} \mathrm{O}_{9}$. Its atomic mass is $227 \mathrm{amu}$. Its heat of formation is $380 \mathrm{~kJ} / \mathrm{mol}$. The propellants we are interested in should have flame temperatures slightly below $1500^{\circ} \mathrm{C}$.

In Table 3 below, we list several propellants. In the first column, we list propellant composition. In the second column, we list the flame temperature. In the third column, we list exhaust velocity into vacuum given an initial pressure of $40 \mathrm{~atm}$ and expansion of 15 . Both temperature and the exhaust velocity are calculated using the program called Rocket Propulsion Analsis [36], which is available online. The fourth column lists the burning rate at $40 \mathrm{~atm}$. The fifth column lists power coefficient. For almost all propellants, the burning rate is approximated by

$$
r_{b}(P)=r_{b}\left(P_{0}\right)\left(\frac{P}{P_{0}}\right)^{n},
$$

where $r_{b}$ is the burning rate, $P$ is pressure, $P_{0}$ is the reference pressure, and $n$ is the power coefficient.

Table 3. Performance of solid propellants (NA—not available).

\begin{tabular}{|c|c|c|c|c|}
\hline $\begin{array}{l}\text { Propellant } \\
\text { Composition }\end{array}$ & $\begin{array}{l}\text { Temperature } \\
\text { at } 40 \mathrm{~atm}\end{array}$ & $\begin{array}{c}v_{e} \text { at } 40 \mathrm{~atm} \\
\text { Exp } 15 \\
\text { Vacuum }\end{array}$ & $\begin{array}{l}\text { Burning } \\
\text { Rate }\end{array}$ & $\begin{array}{l}n \text { Coefficient } \\
\text { at } 40 \text { atm }\end{array}$ \\
\hline $20 \%$ Binder, $72 \%$ AN, $8 \% \operatorname{MgAl}[37]$ & $1280^{\circ} \mathrm{C}$ & $2140 \mathrm{~m} / \mathrm{s}$ & $2.0 \mathrm{~mm} / \mathrm{s}$ & 0.5 \\
\hline $20 \%$ Binder, $68 \%$ AN, $12 \% \mathrm{MgAl}$ & $1450{ }^{\circ} \mathrm{C}$ & $2240 \mathrm{~m} / \mathrm{s}$ & NA & NA \\
\hline $20 \%$ Binder, $64 \%$ AN, $16 \% \mathrm{MgAl}[37]$ & $1700^{\circ} \mathrm{C}$ & $2320 \mathrm{~m} / \mathrm{s}$ & $3.0 \mathrm{~mm} / \mathrm{s}$ & 0.5 \\
\hline $25 \%$ Binder, $60 \% \mathrm{AN}, 15 \% \mathrm{MgAl}[37]$ & $1410^{\circ} \mathrm{C}$ & $2170 \mathrm{~m} / \mathrm{s}$ & $1.6 \mathrm{~mm} / \mathrm{s}$ & 0.7 \\
\hline $\begin{array}{c}17.8 \% \mathrm{HTPB}, 64 \% \text { AN, } \\
14.6 \% \mathrm{Mg}, 3.6 \% \text { AC [38] }\end{array}$ & $1660^{\circ} \mathrm{C}$ & $2270 \mathrm{~m} / \mathrm{s}$ & $2.0 \mathrm{~mm} / \mathrm{s}$ & 0.05 \\
\hline Nitrocellulose $9 \% \mathrm{~N}$ & $1060^{\circ} \mathrm{C}$ & $1990 \mathrm{~m} / \mathrm{s}$ & NA & NA \\
\hline Nitrocellulose $10 \% \mathrm{~N}$ & $1350{ }^{\circ} \mathrm{C}$ & $2090 \mathrm{~m} / \mathrm{s}$ & NA & NA \\
\hline Nitrocellulose $11 \% \mathrm{~N}$ & $1680^{\circ} \mathrm{C}$ & $2200 \mathrm{~m} / \mathrm{s}$ & NA & NA \\
\hline Nitrocellulose $12 \% \mathrm{~N}$ & $2030^{\circ} \mathrm{C}$ & $2290 \mathrm{~m} / \mathrm{s}$ & NA & NA \\
\hline Nitrocellulose $13 \% \mathrm{~N}$ & $2380^{\circ} \mathrm{C}$ & $2420 \mathrm{~m} / \mathrm{s}$ & NA & NA \\
\hline Nitrocellulose $14 \% \mathrm{~N}$ & $2690^{\circ} \mathrm{C}$ & $2530 \mathrm{~m} / \mathrm{s}$ & NA & NA \\
\hline $90 \%$ Nitrocellulose $7.5 \% \mathrm{~N}, 10 \% \mathrm{Mg}$ & $1290{ }^{\circ} \mathrm{C}$ & $2080 \mathrm{~m} / \mathrm{s}$ & NA & NA \\
\hline $90 \%$ Nitrocellulose $8 \% \mathrm{~N}, 10 \% \mathrm{Mg}$ & $1410^{\circ} \mathrm{C}$ & $2130 \mathrm{~m} / \mathrm{s}$ & NA & NA \\
\hline $90 \%$ Nitrocellulose $8.5 \% \mathrm{~N}, 10 \% \mathrm{Mg}$ & $1540^{\circ} \mathrm{C}$ & $2200 \mathrm{~m} / \mathrm{s}$ & NA & NA \\
\hline $\begin{array}{c}70 \% \mathrm{AP}, 15 \% \mathrm{Al}, 15 \% \text { HTPB } \\
\text { Standard Propellant [39] }\end{array}$ & $2880^{\circ} \mathrm{C}$ & $2610 \mathrm{~m} / \mathrm{s}$ & $6.5 \mathrm{~mm} / \mathrm{s}$ & 0.35 \\
\hline $56 \%$ NG, $44 \%$ Cellulose & $1340^{\circ} \mathrm{C}$ & $2090 \mathrm{~m} / \mathrm{s}$ & NA & NA \\
\hline $59 \%$ NG, $41 \%$ Cellulose & $1510^{\circ} \mathrm{C}$ & $2150 \mathrm{~m} / \mathrm{s}$ & NA & NA \\
\hline $66 \%$ NG, 34\% Cellulose [40] (pp. 4-5) & $1950{ }^{\circ} \mathrm{C}$ & $2300 \mathrm{~m} / \mathrm{s}$ & $4.0 \mathrm{~mm} / \mathrm{s}$ & 0.7 \\
\hline 77\% NG, 23\% Cellulose [40] (pp. 4-5) & $2560^{\circ} \mathrm{C}$ & $2530 \mathrm{~m} / \mathrm{s}$ & $7.0 \mathrm{~mm} / \mathrm{s}$ & 0.7 \\
\hline $82.5 \%$ NG, $17.5 \%$ Cellulose [40] (pp. 4-5) & $2790^{\circ} \mathrm{C}$ & $2630 \mathrm{~m} / \mathrm{s}$ & $10 \mathrm{~mm} / \mathrm{s}$ & 0.7 \\
\hline
\end{tabular}


Propellants using an ammonium nitrate oxidizer may experience burn rate instability for low and moderate pressures. More research is needed in order to determine feasibility and cost of using such propellants. Ammonium Dinitramide and Hydrazinium Nitroformate have been proposed as solid propellant oxidizers. Propellant formulations using these oxidizers have excellent performance. The problem with these oxidizers is their cost of hundreds of dollars per kilogram.

Finding a propellant optimal in terms of both cost and properties remains an open problem. For now, we assume that our propellant has flame temperature $1450{ }^{\circ} \mathrm{C}$, burning rate of $2.0 \mathrm{~mm} / \mathrm{s}$, and exhaust velocity of $2100 \mathrm{~m} / \mathrm{s}$. Extrapolation of the data in [41] (p. 151) also predicts the aforementioned combination of burning rate and exhaust velocity. Using the densities of energetic materials in [41] (p. 37), the density of our propellant should be $1.6 \mathrm{~g} / \mathrm{cm}^{3}$.

\subsection{Grain Shape}

The grain shape is the shape of the fuel within the rocket tube. Different rockets use a wide variety of grain shapes illustrated in Figure 5 below:

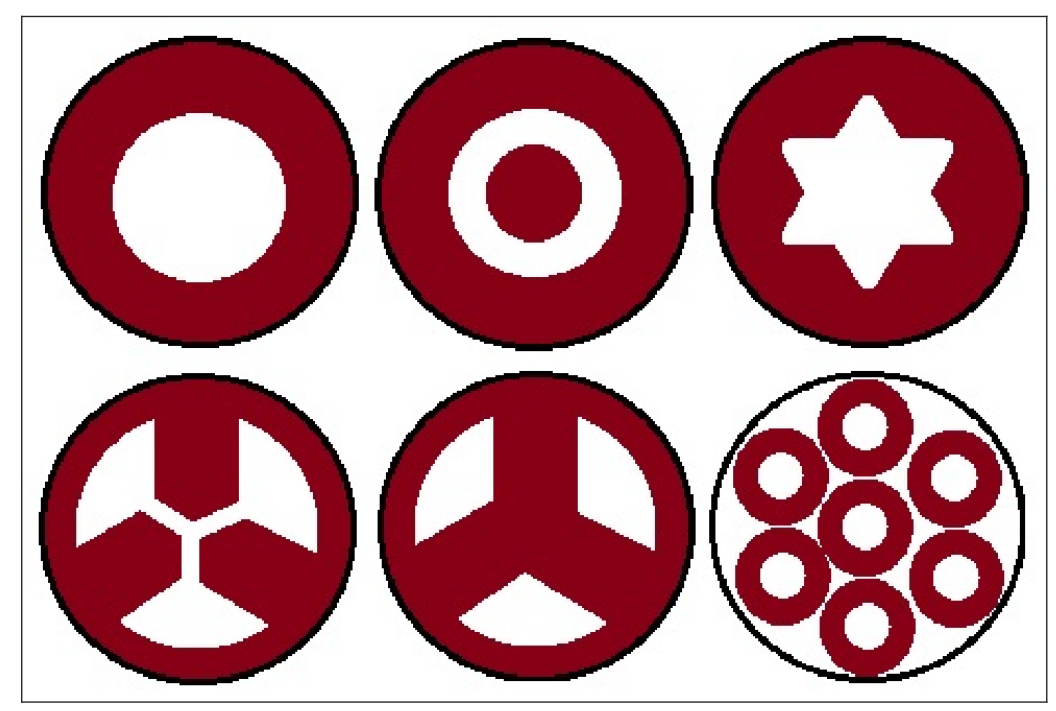

Figure 5. Propellant grain shapes.

The shape may change over the length of the rocket tube. We mention that different types of grain shapes provide different thrust curves. In the present paper, we focus on grain shape providing constant thrust. Propellant loading is the fraction of rocket tube volume occupied by the propellant. The best propellant grain shape for the DLSRR satisfies three requirements. First, the burning propellant surface area should experience minimal change as the propellant is burning. This would ensure steady thrust. Second, the propellant loading should be as high as possible. This would maximise fuel mass ratio within the rocket. Third, the design should be as simple as possible. This would minimize cost.

A diagram of a rocket motor cross-section is presented in Figure 6 below. 


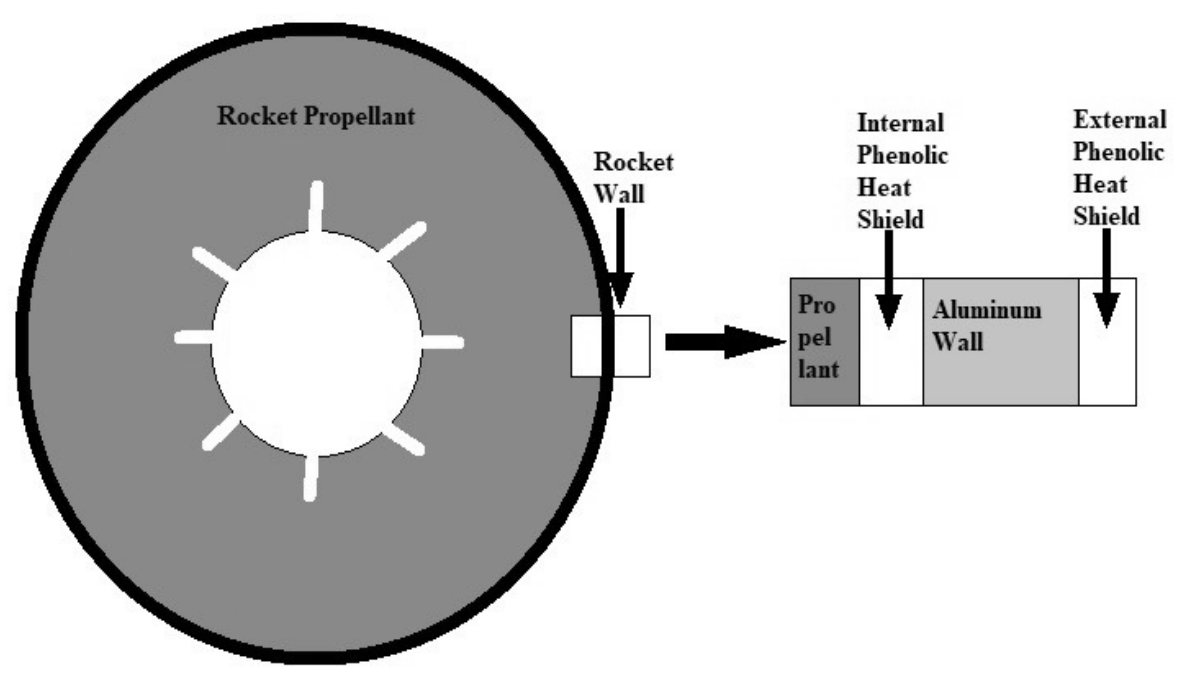

Figure 6. Rocket motor cross section.

Aluminum $6061 \mathrm{~T} 6$ is one of the best candidates for the rocket wall. Aluminum $6061 \mathrm{~T} 6$ pipe of diameter up to $25 \mathrm{~cm}$ and wall thickness $1 \mathrm{~cm}$ is sold for $\$ 14.30$ per $\mathrm{kg}$ pipe weight [42]. It has a density of $2.7 \mathrm{~g} / \mathrm{cm}^{3}$ and tensile yield strength of $2720 \mathrm{~atm}$ [43]. The mass of solid propellant rocket wall for a given volume and pressure is inversely proportional to the wall's specific strength, which is yield strength divided by density. Specific strength has units of

$$
\frac{\mathrm{N} / \mathrm{m}^{2}}{\mathrm{~kg} / \mathrm{m}^{3}}=\frac{\mathrm{N} \cdot \mathrm{m}}{\mathrm{kg}}=\frac{\mathrm{J}}{\mathrm{kg}}
$$

Aluminum $6061 \mathrm{~T} 6$ has a specific strength of $1.15 \times 10^{5} \mathrm{~J} / \mathrm{kg}$. Duralumin and titanium have specific strength about twice as high as Aluminum $6061 \mathrm{~T} 6$, but they are tens of times more expensive than Aluminum $6061 \mathrm{~T} 6$. Composite materials with specific strength of $1.7 \times 10^{5} \mathrm{~J} / \mathrm{kg}$ and price of $\$ 60$ per $\mathrm{kg}$ in 2009 are available. These materials are widely used in compressed natural gas tanks [44]. Currently, these tanks are for sale at about $\$ 60$ per $\mathrm{kg}$ wall material.

\section{Rocket and Warhead Performance}

\subsection{Performance of $30 \mathrm{~cm}$ Drone Launched Short Range Rockets (DLSRR)}

The rocket is shown in Figure 7 below.

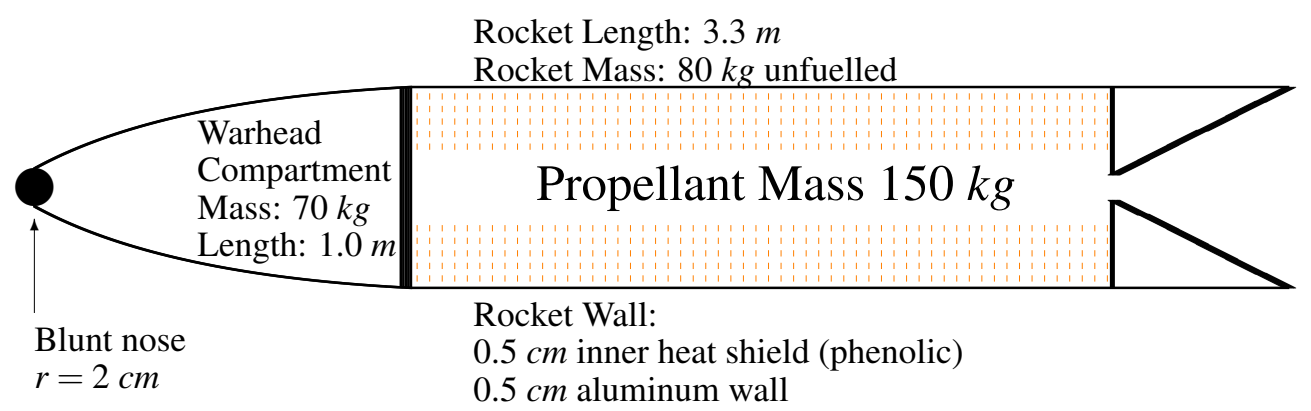

Figure 7. Drone launched short range rocket.

The rocket has a diameter of $30 \mathrm{~cm}$, total mass of $300 \mathrm{~kg}$, and total length of $4.3 \mathrm{~m}$ of which $1.0 \mathrm{~m}$ is the ogive warhead compartment. The propellant mass fraction is $f_{p}=0.50$. We took typical values for a $30 \mathrm{~cm}$ rocket that can be found in the literature. The exhaust velocity is $v_{e}=2100 \mathrm{~m} / \mathrm{s}$. 
Using RASAero software [45], we have calculated the drag coefficient for aforementioned artillery rocket at different Mach numbers and presented in Table 4 below. The RASAero software takes in rocket radius, rocket cylinder length, rocket nose length, and rocket nose shape. The software calculates the drag coefficient.

Table 4. Drag coefficient for $30 \mathrm{~cm}$ rocket.

\begin{tabular}{ccccccccccccc}
\hline $\mathcal{M}$ & 0.25 & 0.50 & 0.75 & 1.00 & 1.25 & 1.50 & 1.75 & 2.00 & 2.25 & 2.50 & 2.75 & 3.00 \\
$C_{d}$ & 0.265 & 0.260 & 0.261 & 0.380 & 0.432 & 0.404 & 0.381 & 0.352 & 0.328 & 0.308 & 0.289 & 0.273 \\
$\mathcal{M}$ & 3.25 & 3.50 & 3.75 & 4.00 & 4.25 & 4.50 & 4.75 & 5.00 & 5.25 & 5.50 & 5.75 & 6.00 \\
$C_{d}$ & 0.259 & 0.246 & 0.235 & 0.225 & 0.216 & 0.208 & 0.200 & 0.193 & 0.187 & 0.181 & 0.175 & 0.168 \\
$\mathcal{M}$ & 6.25 & 6.50 & 6.75 & 7.00 & 7.25 & 7.50 & 7.75 & 8.00 & 8.25 & 8.50 & 8.75 & 9.00 \\
$C_{d}$ & 0.163 & 0.159 & 0.154 & 0.150 & 0.147 & 0.144 & 0.141 & 0.139 & 0.137 & 0.135 & 0.133 & 0.131 \\
\hline
\end{tabular}

The warhead compartment consists of a $10 \mathrm{~kg}$ container which ejects up to $60 \mathrm{~kg}$ of projectiles at the apogee. The projectiles are guided. They are made of high density material like tungsten or depleted uranium.

Performance of DLSRR for several release altitudes, release velocities, and firing times is present in Table 5 below. Three combinations of release altitude and velocity are selected as representative examples. Other combinations are possible. We have presented several grain shapes and propellant compositions. Any combination can be chosen, thus different firing times are possible. For each set of release altitude, release velocity, and propellant burning time, we have calculated the ranges for different firing angles and selected the one giving the longest range. The first row is the engine firing time. The second row is the firing angle producing the greatest range. Rows 3-7 are self-explanatory. Row 8 is the expected range of a warhead released at the apogee. All results have been calculated by Rocket.m program described in Appendix A.

Table 5. Performance of a $30 \mathrm{~cm}$ rocket.

\begin{tabular}{|c|c|c|c|c|c|}
\hline \multicolumn{6}{|c|}{ Release altitude: $12 \mathrm{~km}$. Release velocity: $500 \mathrm{~m} / \mathrm{s}$. } \\
\hline Firing time, $\mathrm{s}$ & 30 & 40 & 50 & 60 & 80 \\
\hline Optimal firing angle, ${ }^{\circ}$ & 54 & 57 & 61 & 64 & 68 \\
\hline Flight time, s & 282 & 288 & 289 & 289 & 277 \\
\hline Drag loss, $\mathrm{m} / \mathrm{s}$ & 98 & 84 & 76 & 69 & 62 \\
\hline Gravity loss, $\mathrm{m} / \mathrm{s}$ & 93 & 131 & 169 & 209 & 285 \\
\hline Rocket Velocity Gain, m/s & 1457 & 1457 & 1457 & 1456 & 1459 \\
\hline Flight apogee, $\mathrm{km}$ & 93 & 94 & 92 & 89 & 77 \\
\hline Range, km & 327 & 317 & 304 & 291 & 263 \\
\hline \multicolumn{6}{|c|}{ Release altitude: 16 km. Release velocity: $600 \mathrm{~m} / \mathrm{s}$. } \\
\hline Firing time, $\mathrm{s}$ & 30 & 40 & 50 & 60 & 80 \\
\hline Optimal firing angle, ${ }^{\circ}$ & 54 & 57 & 59 & 60 & 65 \\
\hline Flight time, $\mathrm{s}$ & 311 & 314 & 311 & 303 & 300 \\
\hline Drag loss, $\mathrm{m} / \mathrm{s}$ & 51 & 45 & 42 & 40 & 35 \\
\hline Gravity loss, $\mathrm{m} / \mathrm{s}$ & 90 & 124 & 158 & 188 & 263 \\
\hline Rocket Velocity Gain, m/s & 1457 & 1457 & 1457 & 1456 & 1456 \\
\hline Flight apogee, $\mathrm{km}$ & 116 & 115 & 110 & 102 & 95 \\
\hline Range, km & 386 & 373 & 361 & 349 & 318 \\
\hline \multicolumn{6}{|c|}{ Release altitude: $20 \mathrm{~km}$. Release velocity: $700 \mathrm{~m} / \mathrm{s}$. } \\
\hline Firing ti & 30 & 40 & 50 & 60 & 80 \\
\hline Optimal firing angle, ${ }^{\circ}$ & 53 & 54 & 56 & 58 & 62 \\
\hline Flight time, s & 320 & 325 & 323 & 322 & 318 \\
\hline Drag loss, $\mathrm{m} / \mathrm{s}$ & 29 & 26 & 24 & 22 & 20 \\
\hline Gravity loss, $\mathrm{m} / \mathrm{s}$ & 82 & 113 & 144 & 176 & 242 \\
\hline Rocket Velocity Gain, m/s & 1457 & 1457 & 1457 & 1456 & 1459 \\
\hline Flight apogee, $\mathrm{km}$ & 125 & 126 & 122 & 118 & 111 \\
\hline Range, km & 444 & 431 & 417 & 403 & 374 \\
\hline
\end{tabular}


For some simulations, there is a small roundoff error of up to $2 \mathrm{~m} / \mathrm{s}$. There may be a very slight variance in $\triangle v$ due to the fact that exhaust velocity depends on ambient air pressure. DLSRR trajectories are plotted in Figure 8 below.
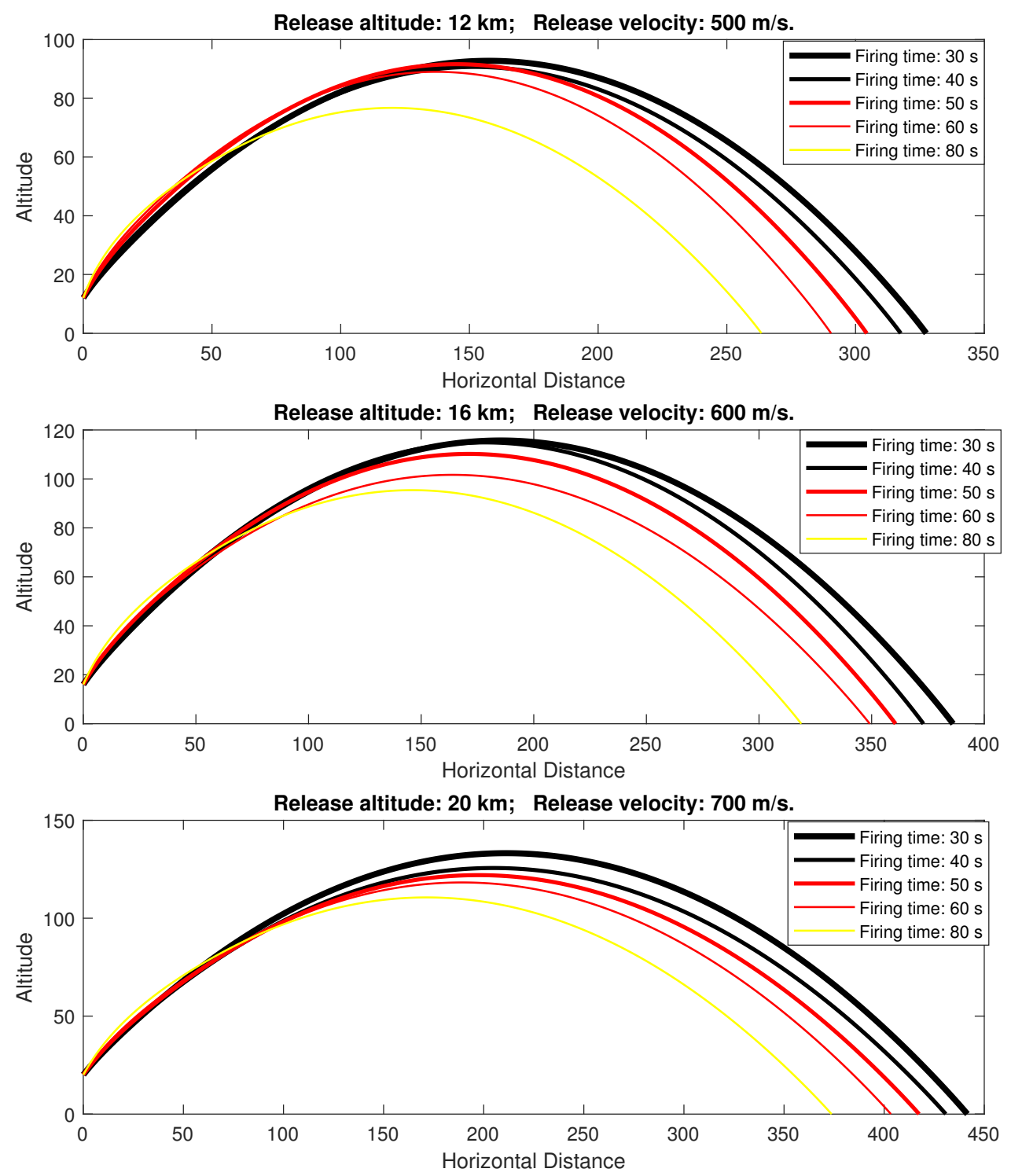

Figure 8. DLSRR trajectories.

\subsection{Impact Velocity Calculation}

\subsubsection{Hypervelocity Projectile}

In this subsection, we calculate the impact velocity for the warhead consisting of the Hypervelocity Projectile (HPV). HPV is described in Section 2.2 and presented in Figure 2. Recall that HPV's weight is $11.4 \mathrm{~kg}$, length $64.2 \mathrm{~cm}$, and caliber $7.83 \mathrm{~cm}$. A $70 \mathrm{~kg}$ warhead compartment can carry up to five such projectiles.

Using RASAero software [45], we have calculated the drag coefficient for the HPV at different Mach numbers and presented in Table 6 below. As we mentioned earlier, the RASAero software takes in rocket radius, rocket cylinder length, rocket nose length, and rocket nose shape. The software calculates the drag coefficient. 
Table 6. Drag coefficient for HPV projectile.

\begin{tabular}{cccccccccccc}
\hline $\mathcal{M}$ & 0.25 & 0.50 & 0.75 & 1.00 & 1.25 & 1.50 & 1.75 & 2.00 & 2.25 & 2.50 & 2.75 \\
$C_{d}$ & 0.208 & 0.203 & 0.202 & 0.289 & 0.336 & 0.325 & 0.292 & 0.265 & 0.243 & 0.225 & 0.208 \\
$\mathcal{M}$ & 3.00 & 3.25 & 3.50 & 3.75 & 4.00 & 4.25 & 4.50 & 4.75 & 5.00 & 5.25 & 5.50 \\
$C_{d}$ & 0.194 & 0.181 & 0.171 & 0.161 & 0.152 & 0.145 & 0.139 & 0.133 & 0.127 & 0.122 & 0.117 \\
$\mathcal{M}$ & 5.75 & 6.00 & 6.25 & 6.50 & 6.75 & 7.00 & 7.25 & 7.50 & 7.75 & 8.00 & \\
$C_{d}$ & 0.112 & 0.106 & 0.103 & 0.099 & 0.095 & 0.091 & 0.089 & 0.087 & 0.085 & 0.083 & \\
\hline
\end{tabular}

In Rocket.m simulations described in Section 5.1, we have calculated DLSRR apogee altitude, DLSRR apogee velocity, and DLSRR apogee horizontal distance. These calculations were performed for release altitudes of $12 \mathrm{~km}, 16 \mathrm{~km}$, and $20 \mathrm{~km}$. Corresponding release velocities were $500 \mathrm{~m} / \mathrm{s}, 600 \mathrm{~m} / \mathrm{s}$, and $700 \mathrm{~m} / \mathrm{s}$. We input the results of Rocket.m simulations and the drag coefficient tabulated in Table 6 above into Impact.m. The program Impact.m calculates the projectiles' ranges, impact velocities, and descent drag loss. The results of calculations are presented in Table 7 below. The first row is the initial velocity. The second row is the firing altitude. The third row is the rocket firing time. The fourth row is the apogee altitude. The fifth row is the apogee velocity. The sixth row is the warhead horizontal range from the firing point. The seventh row is the impact velocity. The eighth row is the descent drag loss.

Table 7. HPV warhead performance.

\begin{tabular}{lrrrrrrrrr}
\hline DLSRR $v_{0}, \mathrm{~m} / \mathrm{s}$ & 500 & 600 & 700 & 500 & 600 & 700 & 500 & 600 & 700 \\
DLSRR $h_{0}, \mathrm{~km}$ & 12 & 16 & 20 & 12 & 16 & 20 & 12 & 16 & 20 \\
DLSRR $t_{f}, s$ & 30 & 30 & 30 & 50 & 50 & 50 & 80 & 80 & 80 \\
\hline Apogee $h, \mathrm{~km}$ & 93 & 116 & 133 & 92 & 110 & 122 & 77 & 95 & 111 \\
Apogee $v, \mathrm{~m} / \mathrm{s}$ & 1239 & 1310 & 1399 & 1170 & 1265 & 1398 & 1151 & 1241 & 1349 \\
\hline Range, $\mathrm{km}$ & 328 & 386 & 442 & 305 & 360 & 418 & 264 & 319 & 374 \\
Impact $v, \mathrm{~m} / \mathrm{s}$ & 1252 & 1422 & 1567 & 1215 & 1372 & 1501 & 1110 & 1269 & 1409 \\
$\triangle v_{\text {loss }}, \mathrm{m} / \mathrm{s}$ & 580 & 574 & 571 & 565 & 568 & 584 & 573 & 579 & 589 \\
\hline
\end{tabular}

As we see from the above table, the HPV has very high aerodynamic drag loss. Even though minimization of drag loss has been an important goal in the design of HPV, the main design goal for HPV was an ability to survive the acceleration of a cannon launch. Rocket launched projectiles do not require the ability to survive extreme acceleration, hence HPV design may be suboptimal for rocket-launched projectiles.

\subsubsection{European Hypersonic Projectile}

The Europrojectile has not been built yet and exists only as a concept. Based on paper [46], we present a sketch in Figure 9 below.

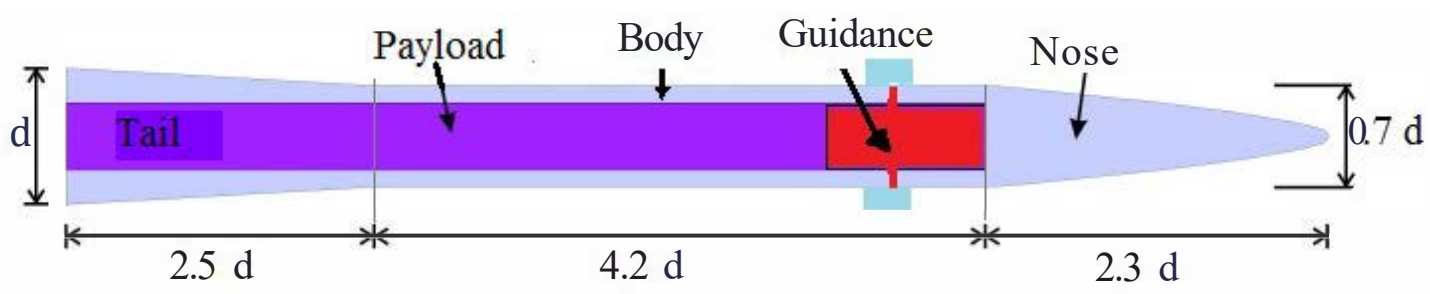

Figure 9. Europrojectile.

In the above figure, $d$ is the base diameter. We will consider several diameters. The length of the projectile is $9 d$. The tail of the projectile is a conical frustum with height $2.5 d$ and radii $0.5 d$ and $0.35 d$. The volume of the tail is 


$$
\frac{\pi}{3} H\left(R_{1}^{2}+R_{1} R_{2}+R_{2}^{2}\right)=\frac{\pi}{3} 2.5 d\left(0.5^{2} d^{2}+0.5 \cdot 0.35 d^{2}+0.35^{2} d^{2}\right)=1.43 d^{3} .
$$

The volume of the cylindrical body of height $4.2 d$ and radius $0.35 d$ is

$$
\pi H R^{2}=\frac{\pi}{4}(4.2 d)(0.7 d)^{2}=1.62 d^{3} .
$$

The volume for LV-Haack nose is derived from the cone equations [47] as $0.56 \pi L R^{2}$, where $L$ is the cone length and $R$ is the cone radius. Thus, in our case, the cone volume is $0.50 d^{3}$. The total volume of the projectile is $3.55 d^{3}$. If the average density of the projectile is $\rho$, then its total mass is

$$
M_{p}=3.55 d^{3} \rho .
$$

The projectile of our choice has caliber $d=7.5 \mathrm{~cm}$, density $\rho=11 \mathrm{~g} / \mathrm{cm}^{3}$, length $67.5 \mathrm{~cm}$, and weight of $16.5 \mathrm{~kg}$. A $70 \mathrm{~kg}$ warhead compartment can carry up to three such projectiles. Using RASAero software [45], we have calculated the drag coefficient for the HPV at different Mach numbers and presented in Table 8 below.

Table 8. Drag coefficient for Europrojectile.

\begin{tabular}{cccccccccccc}
\hline$M$ & 0.25 & 0.50 & 0.75 & 1.00 & 1.25 & 1.50 & 1.75 & 2.00 & 2.25 & 2.50 & 2.75 \\
$C_{d}$ & 0.184 & 0.182 & 0.181 & 0.264 & 0.297 & 0.268 & 0.242 & 0.219 & 0.200 & 0.184 & 0.169 \\
$M$ & 3.00 & 3.25 & 3.50 & 3.75 & 4.00 & 4.25 & 4.50 & 4.75 & 5.00 & 5.25 & 5.50 \\
$C_{d}$ & 0.156 & 0.145 & 0.135 & 0.126 & 0.119 & 0.112 & 0.106 & 0.100 & 0.095 & 0.091 & 0.086 \\
$M$ & 5.75 & 6.00 & 6.25 & 6.50 & 6.75 & 7.00 & 7.25 & 7.05 & 7.75 & 8.00 & \\
$C_{d}$ & 0.081 & 0.076 & 0.072 & 0.069 & 0.066 & 0.062 & 0.060 & 0.058 & 0.056 & 0.055 & \\
\hline
\end{tabular}

We input the results of Rocket.m simulations and the drag coefficient tabulated in Table 6 above into Impact.m. The program Impact.m calculates the projectiles' ranges, impact velocities, and descent drag loss. The results of calculations are presented in Table 9 below. The first row is the initial velocity. The second row is the firing altitude. The third row is the rocket firing time. The fourth row is the apogee altitude. The fifth row is the apogee velocity. The sixth row is the warhead horizontal range from the firing point. The seventh row is the impact velocity. The eighth row is the descent drag loss.

Table 9. Europrojectile warhead performance.

\begin{tabular}{lrrrrrrrrr}
\hline DLSRR $v_{0}, \mathrm{~m} / \mathrm{s}$ & 500 & 600 & 700 & 500 & 600 & 700 & 500 & 600 & 700 \\
DLSRR $h_{0}, \mathrm{~km}$ & 12 & 16 & 20 & 12 & 16 & 20 & 12 & 16 & 20 \\
DLSRR $t_{f}, s$ & 30 & 30 & 30 & 50 & 50 & 50 & 80 & 80 & 80 \\
\hline Apogee $h, \mathrm{~km}$ & 93 & 116 & 133 & 92 & 110 & 122 & 77 & 95 & 111 \\
Apogee $v, \mathrm{~m} / \mathrm{s}$ & 1239 & 1310 & 1399 & 1170 & 1265 & 1398 & 1151 & 1241 & 1349 \\
\hline Range, $\mathrm{km}$ & 328 & 386 & 442 & 305 & 361 & 418 & 264 & 319 & 374 \\
Impact $v, \mathrm{~m} / \mathrm{s}$ & 1555 & 1730 & 1879 & 1507 & 1675 & 1817 & 1400 & 1573 & 1726 \\
$\triangle v_{\text {loss }}, \mathrm{m} / \mathrm{s}$ & 277 & 266 & 260 & 272 & 265 & 268 & 282 & 274 & 272 \\
\hline
\end{tabular}

From the above table, we see that the Europrojectile has high impact velocity. At such velocity, the projectile can inflict considerable damage due to kinetic energy. One type of kinetic energy projectile which inflicts high area damage is a flechette projectile. This projectile explodes at a distance of about a hundred meters from the target releasing thousands of tungsten flechettes weighing $1 \mathrm{~g}$ to $2 \mathrm{~g}$. For a projectile with high impact velocity, the flechettes cause extensive damage [48]. 


\section{Aerodynamic Heating and Thermal Protection}

An object moving through atmosphere at supersonic velocity experiences two types of aerodynamic heating. The first type is shock wave heating. The supersonic object produces a shock wave in front of it. Air temperature behind a shock wave can be as high as $20,000{ }^{\circ} \mathrm{C}$, which has been experienced by the Galileo probe when entering the Jupiter's atmosphere ([49], p. 9). For the rockets, we are considering the temperature of the shocked air will never exceed "mere" $1850{ }^{\circ} \mathrm{C}$, but this temperature is still high.

The second type is skin friction heating. This is due to the high-speed friction of the rocket nose and sides against supersonic or hypersonic stream. Generally, this friction contributes more to overall dynamic heating than the shock wave.

In this work, we use simplified expressions to find an upper bound of heat flux. Exact calculation of heat flux requires extensive calculations using Aerodynamic Theory. Designing an actual thermal protection requires not only advanced theoretical and computational work, but also many laboratory experiments. Most rockets take thousands of expert-years to design [50].

The expressions themselves do not differentiate between heat flux caused by the shock wave and heat flux caused by friction. The heat transfer equations fall into two different classes. These classes represent two types of flow-laminar and turbulent. In this section, we present the expressions for heat flux generated by laminar and turbulent flows.

At the nose of the vehicle, the flow is always laminar. At a short distance from the nose, it becomes turbulent and stays turbulent for the rest of the vehicle length. Generally, turbulent flow transfers a higher heat flux to the wall than a laminar flow.

The expressions used to estimate laminar and turbulent heat fluxes on different types of surfaces have been obtained over decades as mathematical fits to experimental data. These expressions may or may not have deeper physical meanings. Some data patterns may have more than one expression providing a good fit [51-56].

One of the main advantages of DLSRR over conventional long-range ballistic missiles is the relatively low heating of DLSRR during the ascent. The DLSRR reaches high velocities only in significantly rarified atmosphere. Thus, the heat flux and heat load are considerably lower than those experienced by a conventional long-range rocket.

\subsection{General Expressions for Heat Flux}

As a rocket flies through the air at high speed, it experiences aerodynamic heating. The rocket nose experiences laminar flow heating, while the nose cone and rocket cylinder experience turbulent flow heating. Even though some parts of the nose cone may experience laminar flow at high altitudes, turbulent flow heating rate still provides a valid upper bound. In this Subsection, we present general expressions for the heat flux experienced by different points on a rocket surface during ascent.

Recovery temperature is the temperature the surface would have if it lost zero energy by thermal radiation or inward conduction. Recovery temperature is such that air at that temperature has enthalpy $h_{a w}$. Adiabatic wall enthalpy, $h_{a w}$, is given by

$$
h_{a w}=h_{a}+r_{f} \frac{v^{2}}{2}
$$

where $h_{a}$ is the ambient air enthalpy, $v$ is the vehicle velocity, and $r_{f}$ is the recovery factor [51] (p. 9). The recovery factor is a dimensionless number, which is 1 at a stagnation point, and 0.9 for a turbulent boundary flow [52] (p. 100). A crude approximation for the recovery temperature is given by [52] (p. 100):

$$
T_{r}=T_{a}\left(1+0.2 r_{f} \mathcal{M}^{2}\right),
$$

where $T_{r}$ is the recovery temperature, and $T_{a}$ is the ambient air temperature. 


\subsubsection{Stagnation Point Heat Flux}

The stagnation point is a point in a flow field where the local velocity of the fluid is zero [53] (p. 17). The nose tip is the only stagnation point in the flow around a rocket. The laminar heat flux to the stagnation point can be approximated by [51] (p. 6, Equation (40)):

$$
\dot{Q}_{S}^{\text {laminar }}=\dot{Q}_{K} \frac{\mathrm{W}}{\mathrm{m}^{2}} \sqrt{\frac{\rho}{r}} v^{3} \frac{h_{a w}-h_{w}}{h_{a w}-h_{a}},
$$

where $Q_{S}$ denotes the total thermal energy absorbed by the stagnation point, and $\dot{Q}_{S}$ is its time derivative. In Equation (20) above, $\rho$ is the air density measured in $\mathrm{kg} / \mathrm{m}^{3}, r$ is the nose radius in meters, $h_{w}$ is the specific enthalpy of the air at the wall, $h_{a w}$ is the specific enthalpy of the air at a hypothetical adiabatic wall, $h_{a}$ is the specific enthalpy of the ambient air, $v$ is the rocket velocity in $\mathrm{m} / \mathrm{s}$ with respect to air and

$$
\dot{Q}_{K}=1.83 \times 10^{-4} \frac{\mathrm{W}}{\mathrm{m}^{2}}
$$

is a constant. Sutton and Graves give a similar expression [54] with

$$
\dot{Q}_{K}=1.74 \times 10^{-4} \frac{\mathrm{W}}{\mathrm{m}^{2}}
$$

According to Chapman [55],

$$
\dot{Q}_{K}=1.63 \times 10^{-4} \frac{\mathrm{W}}{\mathrm{m}^{2}}
$$

Detra and Hidalgo give a velocity dependent expression [56],

$$
\dot{Q}_{K}=1.45 \times 10^{-4} \frac{\mathrm{W}}{\mathrm{m}^{2}} V_{\mathrm{kps}}^{0.15},
$$

where $V_{\mathrm{kps}}$ is the rocket velocity in kilometers per second. In this work, we use $\dot{Q}_{\mathrm{K}}=1.83 \times 10^{-4} \mathrm{~W} / \mathrm{m}^{2}$, which is the highest heating rate. By including the blackbody radiation emanating from the rocket, we obtain the total heat flux passing through the stagnation point:

$$
\dot{Q}_{S}^{\text {laminar }}=\dot{Q}_{K} \sqrt{\frac{\rho}{r}} v^{3} \frac{h_{a w}-h_{w}}{h_{a w}-h_{a}}-e_{w} \sigma_{B} T_{w}^{4}
$$

where $\sigma_{B}=5.67 \times 10^{-8} \mathrm{~W} / \mathrm{m}^{2} \mathrm{~K}^{4}$ is the Stefan-Boltzmann constant, and $e_{w}<1$ is the wall emissivity.

\subsubsection{General Turbulent Flow Heat Flux}

Turbulent flow heat flux is generally three to six times greater than laminar flow heat flux. The hypersonic flow around any rocket almost always starts out laminar and then turns turbulent. The transition from laminar to turbulent flow occurs at Reynolds number $10^{5} \leq \operatorname{Re} \leq 10^{6}$ [57] (p. 19). The Reynolds number is defined in Equations (28) and (30) below. The flow is turbulent over almost all surface area of the hypersonic vehicles we are considering in this paper.

Below we estimate the skin friction heat flux for general wall temperature and inclination. According to [51] (p. iii), the skin friction heat transfer is defined in terms of Stanton number,

$$
\dot{Q}^{\text {turbulent }}=S t \cdot \rho v\left(h_{a w}-h_{w}\right)=S t \cdot \rho v\left(h_{a w}-h_{a}\right) \frac{h_{a w}-h_{w}}{h_{a w}-h_{a}} .
$$

The enthalpy supplied to the air by the shock wave traveling in front of the moving rocket is equal to $v^{2} / 2$. Thus,

$$
h_{a w}-h_{a}=\frac{v^{2}}{2} .
$$


Substituting (27) into (26), we obtain

$$
\dot{Q}^{\text {turbulent }}=S t \cdot \rho v\left(h_{a w}-h_{a}\right) \frac{h_{a w}-h_{w}}{h_{a w}-h_{a}}=S t \frac{\rho v^{3}}{2} \frac{h_{a w}-h_{w}}{h_{a w}-h_{a}} .
$$

The Stanton number at distance $r y$ from the leading edge can be expressed in terms of skin friction coefficient [58] (p. 305):

$$
S t(r y)=\frac{C_{f}(r y) / 2}{1+13\left(P r^{2 / 3}-1\right) \sqrt{C_{f}(r y) / 2}}
$$

where $C_{f}(r y)$ is the skin friction coefficient at distance $r y$ from the leading edge and Pr is the Prandtl number. The Prandtl number for air is at least 0.71 . The skin friction coefficient for DLSRR, under conditions we are considering, does not exceed 0.008. Substituting these values into (29) we obtain

$$
S t(r y) \leq 0.60 C_{f}(r y) .
$$

Substituting (30) into (28), we obtain

$$
\dot{Q}^{\text {turbulent }}=0.30 C_{f}(r y) \rho v^{3} .
$$

In order to calculate the skin friction coefficient, we introduce the Reynolds number. The Reynolds number for a point on a rocket body is given by [59] (p. 6)

$$
\operatorname{Re}=\frac{\rho v x}{\mu},
$$

where $x$ is the distance of a point from the stagnation point or the leading edge. The dynamic viscosity of the air is [60] (pp. 20-21):

$$
\mu \lesssim 1.7 \times 10^{-5} \frac{\mathrm{kg}}{\mathrm{ms}}\left(\frac{T}{240^{\circ} \mathrm{K}}\right)^{0.7}
$$

The temperature of $240{ }^{\circ} \mathrm{K}$ is close to the ambient air temperature in the region of DLSRR paths. Combining (32) and (33), we obtain the Reynolds number for any point on the rocket surface:

$$
R e \approx 70 \times 10^{6}\left(\frac{\rho}{1 \mathrm{~kg} / \mathrm{m}^{3}}\right)\left(\frac{v}{1 \mathrm{~km} / \mathrm{s}}\right)\left(\frac{x}{1 \mathrm{~m}}\right) .
$$

The above equation is valid for ambient air temperature for most maneuvers. The effect of heating of air by friction and shock wave is described below.

The skin friction coefficient is very well approximated by [49] (p. 4):

$$
C_{f}=0.295 \frac{T_{a}}{T^{*}}\left[\log \left(\operatorname{Re} \frac{T_{a}}{T^{*}} \frac{\mu_{a}}{\mu^{*}}\right)\right]^{-2.45},
$$

where $T_{a}$ is the ambient air temperature, $T^{*}$ is the air temperature at the boundary, $\mu_{a}$ is the ambient air viscosity, and $\mu^{*}$ is the viscosity at the boundary. Expression (35) shows excellent agreement with experiment [49] (p. 8). The temperature at the boundary is the temperature corresponding to the enthalpy $h^{*}$, which is [59] (p. 6):

$$
h^{*}=0.22 h_{a w}+0.50 h_{w}+0.28 h_{a},
$$

where $h_{a w}$ is the adiabatic enthalpy, $h_{w}$ is the enthalpy of air at wall temperature, and $h_{a}$ is the enthalpy of ambient air. The term $T_{a} / T^{*}$ in Equation (35) is due to the fact that the air density is inversely proportional to the air temperature, and the friction force is directly proportional to the air density. 
From (33), air viscosity grows approximately as temperature to the power 0.7 . Thus,

$$
\begin{aligned}
C_{f} & =0.295 \frac{T_{a}}{T^{*}}\left[\log \left(\operatorname{Re} \frac{T_{a}}{T^{*}} \frac{\mu_{a}}{\mu^{*}}\right)\right]^{-2.45} \leq 0.295 \frac{T_{a}}{T^{*}}\left[\log \left(\operatorname{Re}\left(\frac{T_{a}}{T^{*}}\right)^{1.7}\right)\right]^{-2.45} \\
& =0.295 \frac{T_{a}}{T^{*}}\left[\log \operatorname{Re}+1.7 \log \left(\frac{T_{a}}{T^{*}}\right)\right]^{-2.45}=\frac{0.295\left[\log \operatorname{Re}-1.7 \log \left(T^{*} / T_{a}\right)\right]^{-2.45}}{T^{*} / T_{a}} .
\end{aligned}
$$

The range of validity for Equation (37) above is wide enough to describe the conditions for all ascending rockets. In Equation (37) above, log represents log base 10. We express (37) in terms of natural logarithm:

$$
C_{f}=\frac{2.28\left[\ln R e-1.7 \ln \left(T^{*} / T_{a}\right)\right]^{-2.45}}{T^{*} / T_{a}} .
$$

Combining (38) and (31), we obtain

$$
\dot{Q}^{\text {turbulent }}=\frac{0.68\left[\ln R e-1.7 \ln \left(T^{*} / T_{a}\right)\right]^{-2.45}}{T^{*} / T_{a}} \rho v^{3} \frac{h_{a w}-h_{w}}{h_{a w}-h_{a}} .
$$

For the rockets and velocities we are considering, the Reynolds number varies between $1 \times 10^{6}$ and $1 \times 10^{8}$. The quotient $T^{*} / T_{a}$ varies between 1 and 8 . For all values of $R e$ and $T^{*} / T_{a}$ considered, $C_{f}$ is strongly and strictly decreasing function of $T^{*} / T_{a}$. Hence, skin friction coefficient and turbulent heating are strongly decreasing with rising wall temperature.

\subsubsection{Rocket Cylinder}

For the rocket cylinder of DLSRR, the turbulent flow heat flux is calculated by (39) with the Reynolds number Re given by (34). At the base of the rocket cylinder, the distance from the stagnation point is $x=1 \mathrm{~m}$. Substituting this distance into (34), we obtain the Reynolds number for the leading edge:

$$
R e \approx 70 \times 10^{6}\left(\frac{\rho}{1 \mathrm{~kg} / \mathrm{m}^{3}}\right)\left(\frac{v}{1 \mathrm{~km} / \mathrm{s}}\right) .
$$

For further parts of the rocket cylinder, the Reynolds number is higher and the heat flux is a little lower.

\subsubsection{Nose Cone}

Conical shape surface experiences 1.3 times the heat flux experienced by a flat plate [61] (p. 11). Another factor leading to an increase in turbulent flow heating rate on a cone relative to cylinder wall is the fact that the air pressure on the cone will exceed ambient atmospheric pressure. Any shape moving through the air stream with Mach number $\mathcal{M}$ having tangential angle $\theta$ to the air stream will incur a dynamic pressure of

$$
P_{d}=P \frac{\gamma}{2} \mathcal{M}^{2}(\sin \theta)^{2},
$$

where $P$ is the ambient atmospheric pressure. We calculate the total pressure exerted on an inclined surface in an air stream by adding ambient pressure and dynamic pressure. The total pressure will exceed the ambient pressure by a factor of

$$
\frac{P_{w w}}{P}=1+\frac{\gamma}{2} \mathcal{M}^{2}(\sin \theta)^{2} \leq 1+6 \cdot 10^{-6}(\sin \theta)^{2} v^{2},
$$

where $v$ is the rocket velocity in $\mathrm{m} / \mathrm{s}$, and $\theta$ is the angle between the cone surface and the oncoming air stream. The heat transfer rate given in (39) will be multiplied by the same amount. Thus, 


$$
\begin{aligned}
\dot{Q}_{\text {cone }}^{\text {turbulent }} & \leq\left(1+6 \times 10^{-6}(\sin \theta)^{2} v^{2}\right) \\
& \times \frac{0.88\left[\ln R e-1.7 \ln \left(T^{*} / T_{a}\right)\right]^{-2.45}}{T^{*} / T_{a}} \rho v^{3} \frac{h_{a w}-h_{w w}}{h_{a w}-h_{a}},
\end{aligned}
$$

where $T^{*}$ is the temperature for which air enthalpy is given by (36), $T_{a}$ is the air temperature, $T_{w}$ is the rocket wall temperature, and $R e$ is the Reynolds number given by (34).

Using the above information about the aerodynamic heating, we have written a Matlab program ThermalAnalysis.m described in Appendix A. This program calculates the temperatures of DLSRR stagnation point, several points on DLSRR nose cone, and rocket cylinder base during the powered portion of DLSRR ascent. The program takes in the time series data containing ambient air temperature, ambient air density, and rocket velocity. These time series are produced by the program Rocket.m, which is also described in Appendix A.

Equation (25) is used to calculate stagnation point heat flux. Equation (43) is used to calculate the heat flux on the rocket nose cone caused by turbulent flow. All of the aforementioned fluxes are functions of the local rocket wall temperature. The program finds wall temperatures at the stagnation point and several points on rocket nose such that the absorbed heat flux is equal to the heat flux radiated away. These temperatures are determined for all time intervals during the rocket's powered ascent.

Equation (39) is used to calculate the heat flux on the rocket cylinder base caused by the turbulent flow. The cylinder does not radiate away any of absorbed heat. Being a heat sink shield, it absorbs the heat and gets hotter. The program calculates the cylinder base temperature at the end of the powered flight.

The program ThermalAnalysis.m performs calculations for rocket heating. The results of these calculations are presented in Section 6.3.

\subsection{Thermal Protection Systems}

There are three categories of heat shields. These are radiative shields, ablative shields, and heat sink shields. Radiative shields radiate away almost all of the heat flux they receive. They conduct almost no heat. DLSRR nose cone uses a radiative heat shield. Ablative shields absorb the heat flux. The heat is dissipated by pyrolysis and sublimation of the shield material [62] (p. 80). DLSRR does not use ablative heat shields anywhere. Heat sink shields absorb heat flux. These shields generally consist of light metals which can absorb considerable thermal energy without becoming extremely hot. The DLSRR cylinder rocket uses Aluminum 6061 T6 cylinder wall as a "inherent" heat shield. During the rocket flight, the wall experience heating, but not enough to become dysfunctional.

\subsubsection{Radiative Heat Shields}

A typical radiative heat shield consists of three layers. The outermost layer is composed of a thin metal sheet. The metal should be resistant to oxidation and have high emissivity. Emissivity is the "ratio of the radiant flux emitted per unit area to that of an ideal black body at the same temperature" [63] (pp. 2-45). The next layer is flexible thermal insulation composed of ceramic fiber. The innermost layer is the underlying rigid structure. This is the shield used on DLSRR nose cone. In some works, the whole three layer shield is called a metal heat shield [64].

\section{Outermost Layer-Oxidation Resistant Metals}

The outermost layer of the metal heat shield is subject to both high heat flux and hypersonic oncoming wind. This layer must have high melting point and high oxidation resistance. Oxidation resistance of material is defined in terms of its recession rate under the influence of high temperature 
oxidizing environment. The recession rate depends on material, temperature, air density, and oncoming wind velocity. In some cases, recession follows a linear law:

$$
d_{r}(t)=K_{\text {linear }} t
$$

where $d_{r}(t)$ is the recession distance, $t$ is the exposure time, and $K_{\text {linear }}$ is a linear recession constant. The constant $K_{\text {linear }}$ has units of $\mathrm{m} / \mathrm{s}$. Some oxidation-resistant metals are protected from oxidation by an outer oxide layer [65]. This layer is protective for temperatures beyond the oxide melting point. For instance, refractory metals such as tungsten and molybdenum have poor oxidation resistance due to the low melting points of their corresponding oxides. In cases where metal oxide does provide protection, metal recession follows a parabolic law:

$$
d_{r}(t)=\left(K_{\text {parabolic }} t\right)^{1 / 2}
$$

where $d_{r}(t)$ is the recession distance, $t$ is the exposure time, and $K_{\text {parabolic }}$ is a parabolic recession constant. The constant $K_{\text {parabolic }}$ has units of $\mathrm{m}^{2} / \mathrm{s}$.

For temperatures up to $1300{ }^{\circ} \mathrm{C}$, Nickel has good oxidation resistance. In static air at atmospheric pressure and $1300{ }^{\circ} \mathrm{C}$ temperature, it has a parabolic oxidation rate with constant $K_{\text {parabolic }}=2.5 \times 10^{-15} \mathrm{~m}^{2} / \mathrm{s}$ [65]. Under these conditions, it takes $10,000 \mathrm{~s}$ to oxidize a layer of nickel $0.005 \mathrm{~mm}$ thick. Inconel's oxidation resistance is slightly lower. In static air at atmospheric pressure and $1300{ }^{\circ} \mathrm{C}$ temperature, it has parabolic oxidation rate with constant $K_{\text {parabolic }}=7 \times 10^{-14} \mathrm{~m}^{2} / \mathrm{s}[66]$ (p. 19). Nickel and Inconel with oxidised surface have emissivity of at least 0.75 [67] (p. E-386). Inconel 625 sheets $0.5 \mathrm{~mm}$ thick are available at $\$ 380$ per $\mathrm{m}^{2}$ [68]. These sheets have areal density of $4.2 \mathrm{~kg} / \mathrm{m}^{2}$. An alloy containing $80 \%$ Nickel and $20 \%$ chromium has excellent properties and can be reused multiple times as heat shield up to $1200{ }^{\circ} \mathrm{C}$ [64] (p. 1). The oxidized surface of the alloy has emissivity of 0.7 to 0.9 [64] (p. 184). In static air at atmospheric pressure and $1300{ }^{\circ} \mathrm{C}$ temperature, the alloy has parabolic oxidation rate with constant $K_{\text {parabolic }}<2 \times 10^{-15} \mathrm{~m}^{2} / \mathrm{s}$ [64] (p. 207).

Chromium is oxidation-resistant up to $1550^{\circ} \mathrm{C}$ [69]. A layer of chromium oxide protects chromium from rapid oxidation at high temperatures. Pure chromium should have been protected by its oxide up to its melting point of about $1900{ }^{\circ} \mathrm{C}$. Unfortunately, the $\mathrm{Cr}_{2} \mathrm{O}_{3}$ forms eutectic with lower oxides and melts away at $1650{ }^{\circ} \mathrm{C}$ [69]. In air at atmospheric pressure and $1550{ }^{\circ} \mathrm{C}$ temperature, chromium has parabolic oxidation rate with constant $K_{\text {parabolic }}=1 \times 10^{-12} \mathrm{~m}^{2} / \mathrm{s}$ [70].

More expensive metals and alloys are needed to provide oxidation protection at higher temperatures [71]. For the DLSRR nose cone, however, Nickel, Inconel, and Chromium are sufficient.

\section{Second Layer-High Temperature Thermal Insulation}

Relatively inexpensive ceramic felt and cloth thermal isolation are available. CeramFiber thermal insulation works up to $1260{ }^{\circ} \mathrm{C}$. A sheet weighing $3 \mathrm{~kg} / \mathrm{m}^{2}$ costs $\$ 58$ per $\mathrm{m}^{2}$ [72]. Superwool HT Paper $2 \mathrm{~mm}$ thick has areal density of $0.45 \mathrm{~kg} / \mathrm{m}^{2}$, thermal conductivity below $0.25 \mathrm{~W} /\left(\mathrm{m}^{\circ} \mathrm{K}\right)$, and good properties up to $1300{ }^{\circ} \mathrm{C}$ [73] (p. 46). Zirconia Grade ceramic fiber paper works up to $1420{ }^{\circ} \mathrm{C}$. A sheet weighing $3 \mathrm{~kg} / \mathrm{m}^{2}$ costs $\$ 147$ per $\mathrm{m}^{2}$ [74]. All of the aforementioned fibers can resist temperatures $100{ }^{\circ} \mathrm{C}$ higher than their classification for about a minute.

\section{DLSRR Thermal Insulation}

DLSRR nose cone has a simple radiative heat shield. The stagnation point and the first $10 \mathrm{~cm}$ of the cone are covered by a $1 \mathrm{~mm}$ thick chromium sheet. The second layer at that area consists of a $1 \mathrm{~cm}$ thick Zirconia Grade ceramic fiber paper. This combination can withstand temperatures of up to $1520^{\circ} \mathrm{C}$ which is $1793^{\circ} \mathrm{K}$ for duration of SRS ascent. The rest of the nose cone is covered by a $0.5 \mathrm{~mm}$ thick nickel or Inconel sheet. The second layer consists of CeramFiber blanket $1 \mathrm{~cm}$ thick. This shield section can withstand temperatures of up to $1260^{\circ} \mathrm{C}$ which is $1533^{\circ} \mathrm{K}$. 


\subsubsection{Heat Sink Shields}

The heat sink shield consists of three layers similar to metal radiative heat shield. The outermost layer is composed of metal. The next layer is flexible thermal insulation composed of ceramic fiber. The innermost layer is the underlying rigid structure. The difference between heat sink shield and radiative heat shield is the function of the outer layer. Whereas the outer layer of the radiative heat shield radiates away the heat flux, the outer layer of heat sink shield absorbs the thermal energy. Heat sink shields are most useful for absorbing short and powerful heat fluxes. These shields have been used for suborbital vehicles since the 1950s [75] (p. 23).

Inherent heat sink shield is a part of a rocket or aircraft which has another primary function and also fulfills an extra function as a heat shield. For instance, a military aircraft may have armor which can act as a heat sink shield during short-time supersonic maneuvers. A solid rocket's metal shell mainly serves to contain the pressure of fuel grain combustion product. This shell may serve as a inherent heat sink shield as long as it does not overheat during hypersonic flight.

DLSRR has such inherent heat sink shield. As we mentioned in Section 5.1, the rocket cylinder consists of a $0.5 \mathrm{~cm}$ thick aluminum wall. Below, we calculate the heat load such wall can withstand.

Rocket cylinder wall can be heated only so far as it retains tensile strength to hold the solid rocket motor. Aluminum $6061 \mathrm{~T} 6$ is the material composing the artillery rocket cylinder wall. Its yield strength is $283 \mathrm{MPa}$ at $-28{ }^{\circ} \mathrm{C}, 276 \mathrm{MPa}$ at $24^{\circ} \mathrm{C}, 262 \mathrm{MPa}$ at $100{ }^{\circ} \mathrm{C}, 250 \mathrm{MPa}$ at $118^{\circ} \mathrm{C}$, and $214 \mathrm{MPa}$ at $149^{\circ} \mathrm{C}$. On further heating, it rapidly loses strength [43].

It takes $73 \mathrm{~J} / \mathrm{g}$ to heat aluminum from $20^{\circ} \mathrm{C}$ to $100{ }^{\circ} \mathrm{C}$ [63] (pp. 12-190). The $0.5 \mathrm{~cm}$ thick aluminum wall has an areal density of $13.5 \mathrm{~kg} / \mathrm{m}^{2}$. During the rocket motor burning, it can absorb a heat flux of

$$
73 \frac{\mathrm{J}}{\mathrm{g}} \times 1.35 \times 10^{4} \frac{\mathrm{g}}{\mathrm{m}^{2}}=9.9 \times 10^{5} \frac{\mathrm{J}}{\mathrm{m}^{2}} .
$$

As we show in Section 6.3.3, the heat flux at cylinder base is under $1 \mathrm{MJ} / \mathrm{m}^{2}$.

Long-range rockets fired from the ground sustain an order of magnitude higher heat load. These rockets must have extensive outer heat shields. This is one of the reasons such rockets are expensive [52] (pp. 103-106).

\subsection{DLSRR Heating}

In this subsection, we estimate the maximal heat load on various parts of the artillery rocket (DLSRR) during its ascent. The $30 \mathrm{~cm}$ DLSRR is described in great detail in Section 4 . In this Subsection, we describe the heating of three parts of DLSRR: the stagnation point, the nose cone, and the rocket cylinder. The nose cone experiences greater heat flux than the rocket cylinder. The steps in heat flux calculations for the three parts are somewhat different.

The three parts of DLSRR have different heat shields. Both DLSRR stagnation point and DLSRR nose cone use a radiative heat shield described in Section 6.2. The temperature of this shield at any moment depends on the local heat flux. The DLSRR cylinder uses an inherent heat sink shield described in Section 6.2. The temperature of this shield grows slowly almost in proportion to the absorbed heat load. The DLSRR outer shell containing the three aforementioned parts is presented in Figure 10 below.

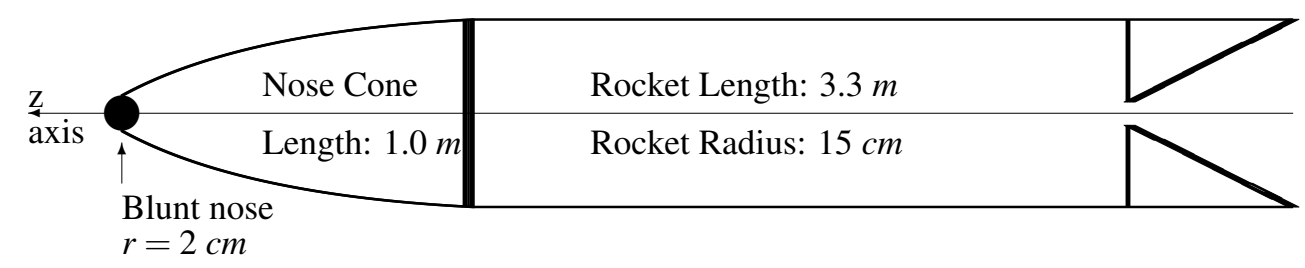

Figure 10. DLSRR outer shell. 


\subsubsection{DLSRR Stagnation Point}

During the rocket ascent, the DLSRR stagnation point experiences laminar flow heating. This heat is radiated away by oxidized chromium covering the stagnation point. The emissivity of oxidized chromium surface is at least 0.6 [67] (p. E-387). The total heat flux to the stagnation point given in (25) is

$$
\dot{Q}_{S}^{\text {laminar }}=\dot{Q}_{K} \sqrt{\frac{\rho}{r}} v^{3} \frac{h_{a w}-h_{w}}{h_{a w}-h_{a}}-e_{w} \sigma_{B} T_{w}^{4} \leq \dot{Q}_{K} \sqrt{\frac{\rho}{r}} v^{3} \frac{h_{a w}-h_{w}}{h_{a w}-h_{a}}-0.6 \sigma_{B} T_{w}^{4},
$$

where $\sigma_{B}=5.67 \times 10^{-8} \mathrm{~W} / \mathrm{m}^{2} \mathrm{~K}^{4}$ is the Stefan-Boltzmann constant. The upper bound for stagnation point temperature is calculated by setting the maximum heat flux to zero:

$$
\dot{Q}_{K} \sqrt{\frac{\rho}{r}} v^{3} \frac{h_{a w}-h_{w}}{h_{a w}-h_{a}}-0.6 \sigma_{B} T_{w}^{4}=0
$$

Notice that, in the above Equation (48), the air enthalpy at wall temperature $h_{w}$ is a function of the wall temperature $T_{w}$.

The program ThermalAnalysis.m uses Equation (48) to calculate stagnation point temperature. This calculation is done for every point on DLSRR trajectory.

\subsubsection{DLSRR Nose Cone}

During the rocket ascent, DLSRR nose cone experiences turbulent flow heating. This heat is radiated away by oxidized Inconel covering the stagnation point. The emissivity of oxidized Inconel surface is at least 0.75 [67] (p. E-387). The total heat flux to the nose cone is obtained by subtracting the radiative heat flux from the convective heat flux given in (43). For reader's convenience, we provide the formula for total heat flux with the notations described below formula (43):

$$
\begin{aligned}
\dot{Q}_{\text {cone }}^{\text {turbulent }} & \leq\left(1+6 \times 10^{-6}(\sin \theta)^{2} v^{2}\right) \\
& \times \frac{0.88\left[\ln R e-1.7 \ln \left(T^{*} / T_{a}\right)\right]^{-2.45}}{T^{*} / T_{a}} \rho v^{3} \frac{h_{a w}-h_{w}}{h_{a w}-h_{a}}-0.75 \sigma_{B} T_{w}^{4} .
\end{aligned}
$$

The angle of inclination, $\theta$, towards the air stream is different for different parts of nose cone. The upper bound for nose cone temperature is calculated by setting the maximum heat flux to zero:

$$
\left(1+6 \times 10^{-6}(\sin \theta)^{2} v^{2}\right) \frac{0.88 \rho v^{3}}{\frac{T^{*}}{T_{a}}\left[\ln R e-1.7 \ln \left(\frac{T^{*}}{T_{a}}\right)\right]^{2.45}} \frac{h_{a w}-h_{w}}{h_{a w}-h_{a}}-0.75 \sigma_{B} T_{w}^{4}=0 .
$$

Notice that, in the above Equation (50), both the air enthalpy at wall temperature $h_{w}$ and boundary air temperature $T^{*}$ are functions of the wall temperature $T_{w}$.

In order to solve Equation (50), we must find the angle of inclination $\theta$ for different points on the nose cone. We present the nose cone in Figure 11 below.

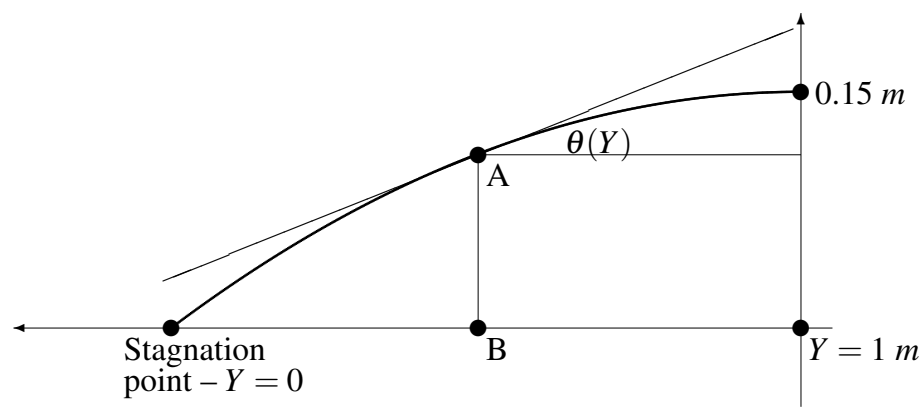

Figure 11. Nose cone. 
Any point $\mathrm{A}$ on the cone can be located in terms of an angular coordinate $\phi \in[0,2 \pi)$ and a non-angular coordinate $Y$. If $B$ is the projection of $A$ onto the $Y$-axis then $Y$ is the distance between $A$ and the stagnation point. Heat flux and heat shield temperature are independent of $\phi$ due to the angular symmetry. Below, we calculate the heat flux and the heat shield temperature for several values of $Y$. For an ogive cone with radius $0.15 \mathrm{~m}$ and length $1.0 \mathrm{~m}$, the inclination of any plane segment at coordinate $Y$ is

$$
\theta(Y) \approx 0.3 \cdot \frac{1 m-Y}{1 m}
$$

The program ThermalAnalysis.m uses Equation (50) to calculate nose cone temperatures at different points on the nose cone as functions of time. This calculation is done for every point on DLSRR trajectory. The heat shield temperatures for DLSRR rocket for different firing altitudes, initial velocities, and rocket firing times are shown in Figure 12 below.

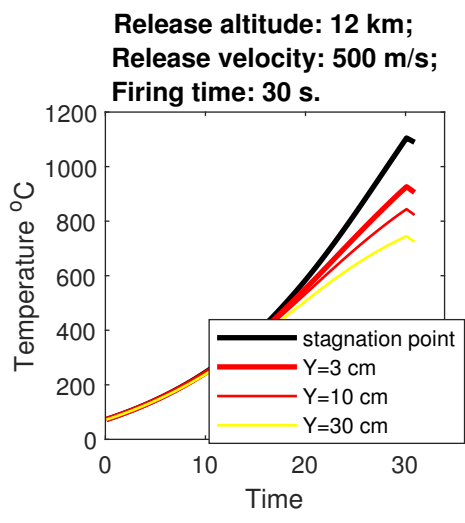

Release altitude: $16 \mathrm{~km}$; Release velocity: $600 \mathrm{~m} / \mathrm{s}$; Firing time: $30 \mathrm{~s}$.

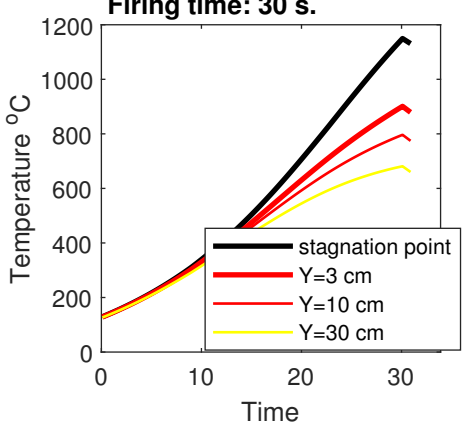

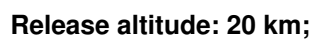

Release velocity: $700 \mathrm{~m} / \mathrm{s}$; Firing time: $30 \mathrm{~s}$.

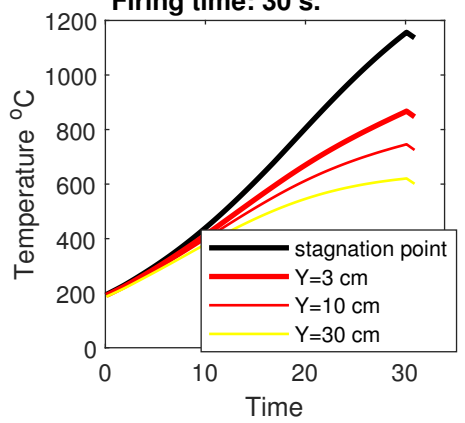

Release altitude: $\mathbf{1 2} \mathbf{~ k m ; ~}$ Release velocity: $500 \mathrm{~m} / \mathrm{s}$; Firing time: $50 \mathrm{~s}$.

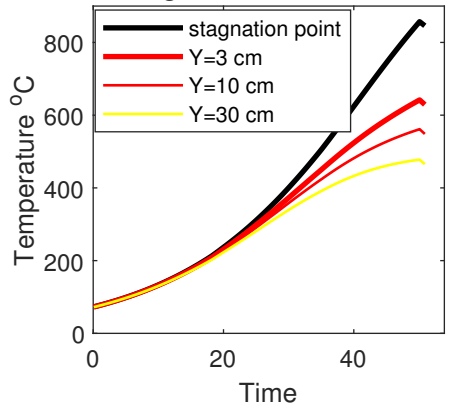

Release altitude: 16 km; Release velocity: $600 \mathrm{~m} / \mathrm{s}$; Firing time: $\mathbf{5 0} \mathrm{s}$.

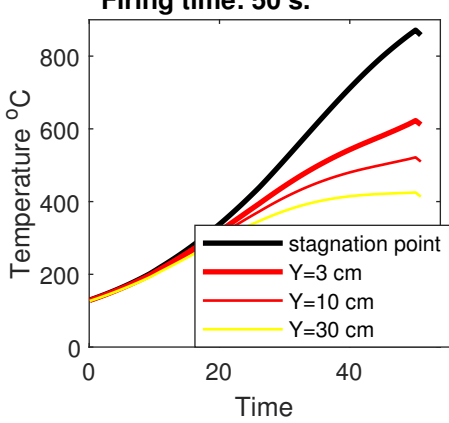

Release altitude: $\mathbf{2 0} \mathbf{~ k m ; ~}$ Release velocity: $700 \mathrm{~m} / \mathrm{s}$; Firing time: $\mathbf{5 0} \mathrm{s}$.

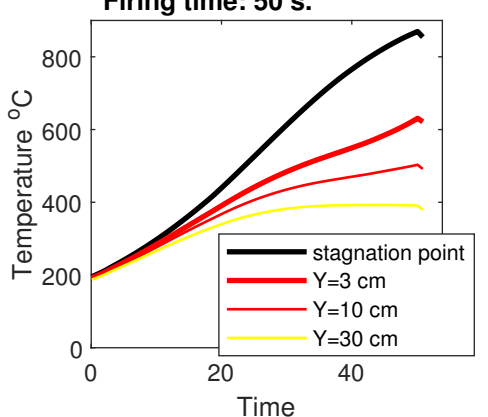

Release altitude: 12 km; Release velocity: $500 \mathrm{~m} / \mathrm{s}$; Firing time: $80 \mathrm{~s}$.

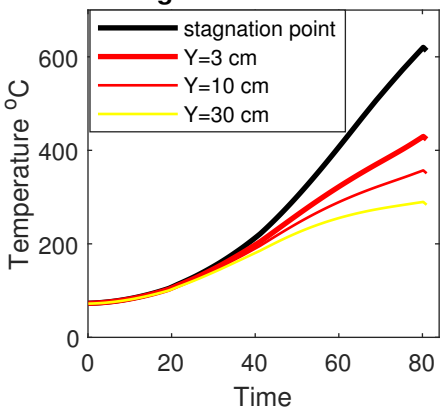

Release altitude: $\mathbf{1 6}$ km; Release velocity: $600 \mathrm{~m} / \mathrm{s}$;

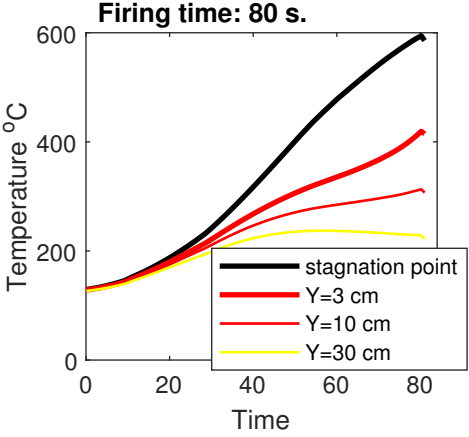

Release altitude: $\mathbf{2 0}$ km; Release velocity: $700 \mathrm{~m} / \mathrm{s}$; Firing time: $80 \mathrm{~s}$.

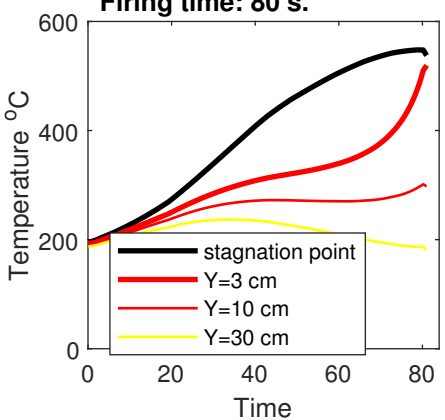

Figure 12. Aerodynamic heating of the DLSRR nose cone. 
All of the maximum temperatures are within the capabilities of three-layered radiative heat shields described in Section 6.2. The severest conditions arise when the rocket firing time is the shortest-30 s. The maximum temperature of under $1200{ }^{\circ} \mathrm{C}$ is reached for a few seconds. Not only chromium, but also nickel and Inconel can easily withstand such temperature.

The heat flux at the stagnation point is proportional to $\sqrt{\rho}$. The heat flux on the nose cone is proportional to $\rho$, where $\rho$ is the ambient air density. As we see on the last plot of the last row, the heat flux $3 \mathrm{~cm}$ from stagnation point approaches the heat flux at the stagnation point as the rocket ascends.

\subsubsection{DLSRR Cylinder}

The turbulent flow heating rate is given by (43). All the heat is absorbed by the $0.5 \mathrm{~cm}$ thick aluminum rocket body. Almost no heat is radiated away. Assuming DLSRR body starts out at $20^{\circ} \mathrm{C}$, the program ThermalAnalysis.m calculates how much the rocket body heats up during the motor firing. After firing, the rocket body may absorb more heat, but it will have no effect on rocket performance. The temperature of the rocket cylinder base after firing is tabulated in Table 10.

Table 10. Rocket cylinder base heating.

\begin{tabular}{crrrrr}
\hline Firing Time & $30 \mathrm{~s}$ & $40 \mathrm{~s}$ & $50 \mathrm{~s}$ & $60 \mathrm{~s}$ & $80 \mathrm{~s}$ \\
\hline$H=12 \mathrm{~km}, v=500 \mathrm{~m} / \mathrm{s}$ & $94^{\circ} \mathrm{C}$ & $81^{\circ} \mathrm{C}$ & $68^{\circ} \mathrm{C}$ & $58{ }^{\circ} \mathrm{C}$ & $47^{\circ} \mathrm{C}$ \\
$H=16 \mathrm{~km}, v=600 \mathrm{~m} / \mathrm{s}$ & $75^{\circ} \mathrm{C}$ & $66^{\circ} \mathrm{C}$ & $59^{\circ} \mathrm{C}$ & $55^{\circ} \mathrm{C}$ & $46^{\circ} \mathrm{C}$ \\
$H=20 \mathrm{~km}, v=700 \mathrm{~m} / \mathrm{s}$ & $61^{\circ} \mathrm{C}$ & $56^{\circ} \mathrm{C}$ & $52^{\circ} \mathrm{C}$ & $48^{\circ} \mathrm{C}$ & $43^{\circ} \mathrm{C}$ \\
\hline
\end{tabular}

For combinations of rocket altitude, velocity, and firing time, rocket cylinder heating presents no problem.

\section{Conclusions}

In this work, we have demonstrated the feasibility of drone launched short range rockets launched from a rocket launcher aircraft. DLSRR deliver warheads to targets at a distance of $263 \mathrm{~km}$ to $442 \mathrm{~km}$ with impact velocity of $1400 \mathrm{~m} / \mathrm{s}$ to $1880 \mathrm{~m} / \mathrm{s}$. RLA never approaches the target closer than $220 \mathrm{~km}$, making it much less vulnerable to anti-aircraft weapons than modern fighters and bombers.

The cost of delivery of munitions by the DLSRR should be much lower than the cost of delivery of munitions by modern short range ballistic missiles (SRBM). This is the case due to the greatly reduced requirements placed on the DLSRR compared to TBM. First, DLSRR requires much lower $\triangle v$ than SRBM. Second, DLSRR can burn fuel over $30 s$ to $80 s$ which is much slower than most modern TBMs. Third, as we have shown in Section 6.3, the DLSRR reaches high velocity in high stratosphere and experience only moderate heating. Stagnation point temperature never exceeds $1200^{\circ} \mathrm{C}$, and nose cone temperature never exceeds $960^{\circ} \mathrm{C}$. Such temperatures require relatively inexpensive heat protection.

A DLSRR having an initial mass of $300 \mathrm{~kg}$ can deliver a $60 \mathrm{~kg}$ charge to the target. The charge can consist of one or more projectiles. The ranges and impact velocities for a warhead containing four Europrojectiles are listed in Table 9. High release altitude and velocity combined with shorter burning times increase the warhead's range and impact velocity. The same factors increase launch cost.

Funding: This research received no external funding.

Conflicts of Interest: The author declares no conflict of interest. 


\section{Abbreviations}

\section{General}

ATACMS - army tactical missile system (USA)

$C E P$-circular error probability

DF-Dong-Feng ballistic missiles (China)

$D L S R R$ - drone launched short range rockets

GMLRS—guided multiple launch rocket system (USA)

$H P V$ - hypervelocity projectile

$J D A M$ - joint direct attack munition (guidance kit for any bomb)

$L O R A$ - long range attack missile (Israel)

$M K V$-multiple kill vehicle

MLRS—multiple launch rocket system

$P G K$ - precision guidance kit

RASAero-aerodynamic analysis and flight simulation software

$R L A$-rocket launcher aircraft

$R P A$ - rocket propulsion analysis

$S A M$ - surface to air missile

$S R B M$ — short range ballistic missiles

TBM-theatre ballistic missile

Chemicals

$A P$-ammonium perchlorate

$A N$-ammonium nitrate

HTPB - hydroxyl-terminated polybutadiene

\section{Appendix A. Programs Used}

Rocket.m performs calculations for the DLSRR. The user inputs DLSRR's mass, diameter, drag coefficient, propellant mass fraction, exhaust velocity, initial inclination, and propellant burning time. Effective frontal area of the rocket is

$$
A=\frac{\pi}{4} d^{2} .
$$

While the rocket engine is burning, the thrust is obtained by combining (2) and (3):

$$
F_{t}=\frac{M f_{p}}{t_{b}} v_{e},
$$

where $M$ is the rocket mass, $f_{p}$ is the propellant mass fraction, $t_{b}$ is the engine burning time, and $v_{e}$ is the exhaust velocity. Using these data, the program starts to perform iterative calculations on the rocket.

At time $t=0$, Rocket.m has the following: rocket's mass $M$; rocket's coordinates in $x y$-plane, where $x$ is the horizontal distance and $y$ is the altitude; rocket's velocity $\mathbf{v}$-which has horizontal component $v_{x}$ and vertical component $v_{y}$. Rocket.m uses the rocket's altitude to determine air density $\rho$ and sonic velocity $v_{s}$ at time $t=0$. For air density as a function of altitude, we use US Standard Atmosphere 1976. Rocket.m calculates the Mach number as $\mathcal{M}=v / v_{s}$. The drag coefficient $C_{d}$ is determined from the Mach number. The drag force is given by (1):

$$
F_{d}=C_{d}(\mathcal{M}) \frac{\rho v^{2} A}{2} .
$$

The drag force acts in the direction opposite of rocket motion. After the rocket's engine burns out, $F_{d}=0$. Rocket acceleration is derived from all forces acting on the rocket as shown in Figure 3:

$$
\mathbf{a}=\frac{F_{t}-F_{d}}{M(t)} \hat{v}-g \hat{y}
$$


where $\hat{v}$ is a unit vector in the direction of rocket motion, and $\hat{y}$ is a unit vector in $y$ or upward direction.

Rocket.m uses the information given in the above paragraph to calculate similar information at a time $d t$. If the rocket's engines are still burning, then the rocket's mass has decreased by the mass of propellent consumed:

$$
d M=\frac{M f_{p}}{t_{b}} d t
$$

Otherwise, the rocket mass stays constant. The rocket's velocity has changed by

$$
\mathbf{v}(\mathbf{t}+\mathbf{d t})=\mathbf{v}(\mathbf{t})+\mathbf{a}(\mathbf{t}) d t .
$$

The rocket's position has changed by

$$
\mathbf{r}(\mathbf{t}+\mathbf{d t})=\mathbf{r}(\mathbf{t})+\mathbf{v}(\mathbf{t}) d t
$$

Based on the new mass, position, and velocity, Rocket.m calculates the rocket's drag force and acceleration at time $d t$.

Rocket.m performs another iteration obtaining the rocket's drag force and acceleration at time $2 d t$. Rocket.m performs many iterations, until the rocket reaches its apogee-the maximal ascent. Generally, $d t=0.1 \mathrm{~s}$ and it takes $140 \mathrm{~s}$ to $160 \mathrm{~s}$ for the rocket to reach the apogee. Rocket.m performs 1400 to 1600 iterations within a few seconds.

Rocket.m calculates DLSRR's flight apogee altitude $y$, flight apogee horizontal velocity $v_{x}$, and flight apogee horizontal coordinate $x$. Recall that apogee vertical velocity is $v_{y}=0$. Rocket.m also calculates DLSRR's drag loss by Equation (7) and gravity loss by Equation (12).

Rocket.m produces a time series of DLSRR's coordinates $(x, y)$, and velocity $\mathbf{v}=\left(v_{x}, v_{y}\right)$ with time interval $d t$. The time series of ambient air densities and temperatures determined by altitude $y$ as well as the Mach numbers are also recorded.

Impact.m performs calculations on the projectiles released at the apogee. The user inputs the projectile's mass, diameter, drag coefficient, apogee altitude, apogee, velocity, and apogee horizontal coordinate. The program calculates impact distance and velocity.

Mathematically, Impact.m is a simplified version of Rocket.m. As the rocket reaches the apogee, it releases one or more warhead. The warhead(s) keep the rocket's horizontal and vertical coordinates $(x, y)$. They keep the rocket's horizontal velocity $v_{x}$, and vertical velocity, which is 0 at the apogee. The warhead(s) have a new caliber $d_{1} \ll d$, and hence a new frontal area

$$
A_{1}=\frac{\pi}{4} d_{1}^{2}
$$

They also have a new mass $M_{1} \ll M$, which stays the same throughout the descent. The warhead(s) have new drag coefficient dependence on Mach number $C_{d 1}(\mathcal{M})$.

As the warhead(s) descend from the apogee to the target, Impact.m calculates their acceleration, velocity, and coordinate for each time increment $d t$. Drag force is calculated by Equation (A3) with the new frontal area and drag coefficient function. Acceleration is calculated by

$$
\mathbf{a}=-\frac{F_{d}}{M(t)} \hat{v}-g \hat{y},
$$

where $\hat{v}$ is a unit vector in the direction of rocket motion, and $\hat{y}$ is a unit vector in $y$ or upward direction.

Impact.m calculates warhead's descent time, impact velocity, and horizontal distance of the impact. Impact.m also calculates the warhead's drag loss by Equation (7). The warhead experiences no gravity loss during the descent. The combination of Rocket.m and Impact.m calculate the warheads horizontal range from the point of rocket release, and the flight time from rocket firing to impact.

ThermalAnalysis.m calculates the temperatures of SSR stagnation point, several points on SSR nose cone, and rocket cylinder base during the powered portion of SSR ascent. The program takes 
in the time series data containing ambient air temperature, ambient air density, and rocket velocity. These time series are produced by Rocket.m.

For every time interval $d t$, ThermalAnalysis.m solves Equation (48) for the stagnation point wall temperature. Likewise, for every time interval $d t$, ThermalAnalysis.m solves Equation (50) for wall temperature at several points on the rocket's nose. Notice that the temperatures are found for each time independently of temperatures in the previous times.

ThermalAnalysis.m uses Equation (39) to calculate the heat flux on the rocket cylinder base caused by the turbulent flow. The cylinder does not radiate away any of absorbed heat. Being a heat sink shield, it absorbs the heat and gets hotter. ThermalAnalysis.m assumes that the rocket cylinder base starts at $20^{\circ} \mathrm{C}$, and calculates the time series of rocket base temperatures as the rocket base absorbs heat flux. ThermalAnalysis.m displays the cylinder base temperature at the end of rocket firing.

Rocket wall temperature time series at stagnation point as well as distances of $3 \mathrm{~cm}, 10 \mathrm{~cm}$, and $30 \mathrm{~cm}$ from the stagnation point are plotted in Figure 12. Cylinder base temperature at the end of rocket firing is presented in Table 10.

\section{References}

1. National Research Council (U.S.). Reusable Booster System: Review and Assessment; National Academies Press: Washington, DC, USA, 2012.

2. Becker, J. Militarizing Musk, War on The Rocks. 2016. Available online: https://warontherocks.com/2016/ 05/militarizing-musk/ (accessed on 19 April 2020).

3. Perrimond, G. 1944-2001: The Threat of Theatre Ballistic Missiles; Supplément à TTU Europe: Paris, France, 2002.

4. Wood, J. Russia, the Asymmetric Threat to the United States: A Potent Mixture of Energy and Missiles; Praeger Security International: Santa Barbara, CA, USA, 2009.

5. Parker, S.; Pang, A. The M270 Multiple Rocket Launcher; Capstone Press: Mankato, MN, USA, 2008.

6. Office of the Under Secretary of Defense (Comptroller). Procurement Programs, Department of Defense Budget Fiscal Year 2016; Office of the Under Secretary of Defense: Washington, DC, USA, 2015.

7. Eshel, T. Israel Tests Sea-Launched LORA Missile, Defense Update. 20 June 2017. Available online: http: // defense-update.com/20170620_lora-2.html (accessed on 7 March 2018).

8. Heginbotham, E. The US-China Military Scorecard: Forces, Geography, and the Evolving Balance of Power, 1996-2017; RAND: Santa Monica, CA, USA, 2015.

9. US Department of Defense (DoD). Annual Report to Congress: Military and Security Developments Involving the People's Republic of China; US Department of Defense: Washington, DC, USA, 2017.

10. Wunderle, W.D. US Army Weapons Systems 2009; Skyhorse Pub: New York, NY, USA, 2008.

11. Prenatt, J.; Hook, A. Katyusha: Russian Multiple Rocket Launchers 1941-Present; Bloomsbury Publishing Place: London, UK, 2016.

12. AR3 Multiple Launch Rocket System. Available online: http://www.military-today.com/artillery/ar3.htm (accessed on 14 January 2018).

13. Turner, P.E. New and Evolving Armaments and Subsystems for Future Conflicts; Precision Fires Rocket and Missile Systems: Huntsville, AL, USA, 2016.

14. Merkley, J.A. Trident II Missiles: Capability, Costs, and Alternatives; Congress of the U.S., Congressional Budget Office: Washington, DC, USA, 1986.

15. Gormley, D.M. Dealing with the Threat of Cruise Missiles; Routledge: Abingdon, UK, 2017.

16. Technical tune to Agni test before talks. In Telegraph; Telegraph Media Group: London, UK, 2004.

17. Watts, B.D. Six Decades of Guided Munitions and Battle Networks: Progress and Prospects; Center for Strategic and Budgetary Assessments: Washington, DC, USA, 2007.

18. Bogan, J. Boeing boosts production of precision-guided bomb kits made in St. Charles to fight ongoing wars by air. Saint Louis Today, 27 January 2017.

19. Fresconi, F.; Celmins, I.; Silton, S.; Costello, M. High Maneuverability Projectile Flight Using Low Cost Components. Aerosp. Sci. Technol. 2015, 41, 175-188. [CrossRef]

20. Biass, E.H. Compendium Artillery. Armada Int. 2015, 39, 1-54. 
21. Foss, C. Smart ammo: precision-guided munitions for field artillery. Jane'S Def. Wkly. 2015, 6, 1-14.

22. ATK's Precision Guidance Kit for artillery projectiles now approved for production. In Army Recognition; 2015. Available online: https:/ / www.armyrecognition.com/february_2015_global_defense_security_news_uk/ atk_s_precision_guidance_kit_for_artillery_projectiles_now_approved_for_production.html (accessed on 5 June 2020).

23. Burke, P.G.; Pergolizzi, A. XM1156 Precision Guidance Kit (PGK) Overview. In Proceedings of the 2010 Fuze Conference, Kansas City, MO, USA, 11-13 May 2010.

24. Forrester, A. Orbital ATK Reaches Milestone in M1156 Precision Guidance Kit Production. Govconwire. 2018. Available online: https:/ / www.govconwire.com/2018/05/orbital-atk-reaches-milestone-in-m1156precision-guidance-kit-production (accessed on 9 June 2019).

25. Wang, B. Israel Converts Artillery into a Precision Guided Weapons. In Next, Big Future. 2017. Available online: https://www.nextbigfuture.com/2017/10/israel-converts-artillery-into-a-precisionguided-weapons.html (accessed on 5 June 2020).

26. O'Rourke, R. Navy Lasers, Railgun, and Hypervelocity Projectile: Background and Issues for Congress; Congressional Research Service 7-5700: Washington, DC, USA, 2015.

27. Nemets, A. Conflict with Russia: Part I E, Part 2; Xlibris Corporation: Bloomington, IN, USA, 2015.

28. O'Rourke, R. Sea-Based Ballistic Missile Defense: Background and Issues for Congress; Congressional Research Service, Library of Congress: Washington, DC, USA, 2009.

29. O'Rourke, R. Navy Aegis Ballistic Missile Defense (bmd) Program: Background and Issues for Congress; Congressional Research Service: Washington, DC, USA, 2014.

30. Silverstone, P.H. The Navy of the Nuclear Age, 1947-2007; Routledge: New York, NY, USA, 2009; p. xxvi.

31. Tsiolkovski, K.; Tikhonravov, M.K. Works on Rocket Technology; National Aeronautics and Space Administration: Washington, DC, USA, 1965.

32. Cohen, N.S.; Flanigan, D.A. Mechanisms and Models of Solid-Propellant Burn Rate Temperature Sensitivity-A Review. AIAA J. 1985, 23, 1538-1547. [CrossRef]

33. Biblarz, O.; Sutton, G.P. Rocket Propulsion Elements, 8th ed.; John Wiley \& Sons, Inc.: Hoboken, NJ, USA, 2010.

34. Jain, S.R.; Oommen, C. Ammonium nitrate: A promising rocket propellant oxidizer. J. Hazard. Mater. 1999, 67, 253-281.

35. Caveny, L.H.; Felsheim, C.R.; Summerfield, M. Burning Rate Measurement of Thin Sheets of Double Base Prpopellant; Princeton University: Princeton, NJ, USA, 1975.

36. Ponomarenko, I.A. Rocket Propulsion Analysis. V 1.2.6, Lite Edition 2011, Cologne, Germany. 2011. Available online: http:/ / www.propulsion-analysis.com (accessed on 5 June 2014).

37. Brewster, Q.; Ishihara, A.; Sheridan, T. Ammonium nitrate-magnesium propellant combustion and heat transfer mechanisms. J. Propuls. Power 1992, 2, 760-769. [CrossRef]

38. Azuma,Y.; Murata, H.; Simoda, M.; Tohara, T. Effect of magnalium (Mg-Al alloy) on combustion characteristics of ammonium nitrate-based solid propellant. Sci. Technol. Energ. Mater. 2000, 61, 58-66.

39. Northam, G.B. Effects of Propellant Composition Variables on Acceleration-Induced Burning-Rate Augmentation of Solid Propellants; NASA Langley Research Center: Hampton, VA, USA, 1972.

40. Lengellé, G.; Duterque, J.; Trubert, J.F. Combustion of Solid Propellants; Research Scientists, Energetics Department Office National Détudes et de Recherches Aérospatiales (ONERA): Bordeaux, France, 2004.

41. Kubota, N. Propellants and Explosives; Wiley-VCH Verlag GmbH \& Co. KGaA: Weinheim, Germany, 2007.

42. OnlineMetals.com, Web. Available online: https://www.onlinemetals.com/ (accessed on 14 May 2019).

43. Aluminum 6061-T6; 6061-T651, MatWeb, Your Source for Materials Information. Available online: http: / /www.matweb.com/SpecificMaterial.asp?bassnum=MA6061t6> (accessed on 4 September 2019).

44. Innovation in Composite CNG Cylinders. In JEC Asia 2009 Automotive E Mass Transport Forum; Owens Corning: Toledo, OH, USA, 2009.

45. Rogers, C.E.; Cooper, D. RASAero II, Rocket Aerodynamic Analysis and Flight Simulation Software; V 1.0.1; Rogers Aeroscience: Lancaster, CA, USA, 2016.

46. Hundertmark, S.; Lancelle, D. A Scenario for a Future European Shipboard Railgun. In Proceedings of the 17th International Symposium on Electromag, Launch Tech. (EML), San Diego, CA, USA, 7-11 July 2014.

47. Crowell, G.A. The Descriptive Geometry of Nose Cone, Scribd. 1996. Available online: http:/ / www.scribd. com/doc/60921375/ (accessed on 5 June 2019). 
48. McNab, I.R.; Fish, S.; Stefani, F. Parameters for an Electromagnetic Naval Railgun. IEEE Trans. Magn. 2001, 37, 223-228. [CrossRef]

49. Kulfan, R.M. Historic Background on Flat Plate Turbulent Flow Skin Friction and Boundary Layer Growth; HSR Airframe Technical Review: Los Angeles, CA, USA, 1998.

50. Woodward, D. Space Launch Vehicle Design. Master's Thesis, Department of Mechanical and Aerospace Engineering, University of Texas at Arlington, Arlington, TX, USA, 2017.

51. Tauber, M.E. A Review of High-Speed, Convective, Heat-Transfer Computation Methods; NASA Technical Paper 2914; Ames Research Center: Mountain View, CA, USA, 1989.

52. Fleeman, E.L. Tactical Missile Design; Educational Series; AIAA: Reston, VA, USA, 2001.

53. Clancy, L.J. Aerodynamics; Pitman Publ. Lim.: London, UK, 1975.

54. Sutton, K.; Graves, R.A. A General Stagnation Point Convective Heating Equation for Arbitrary Gas Mixtures; NASA TR-R-376; NASA: Washington, DC, USA, 1971.

55. Chapman, G.T. Theoretical Laminar Convective Heat Transfer \& Boundary Layer Characteristics on Cones at Speeds to $24 \mathrm{~km} / \mathrm{s}$; NASA TN D-2463; NASA: Washington, DC, USA, 1964.

56. Detra, R.W.; Hidalgo, H. Generalized heat transfer formulas and graphs for nose cone re-entry into the atmosphere. ARS J. 1961, 31, 318-321. [CrossRef]

57. Trinh, K.T.; Tuoc, K. On The Critical Reynolds Number For Transition From Laminar to Turbulent Flow. arXiv 2010, arXiv:1007.0810.

58. Lienhard, J., IV; Lienhard, J.V. A Heat Transfer Textbook, 3rd ed.; Phlogiston Press: Cambridge, MA, USA, 2001.

59. Higgins, K. Comparison of Engineering Correlations for Predicting Heat Transfer in Zero-pressure-gradient Compressible Boundary Layers with CFD and Experimental Data. Defence Science and Technology Organisation. 2008. Available online: http://www.dsto.defence.gov.au/corporate/reports/DSTO-TR2159.pdf (accessed on 11 September 2019).

60. Gottlieb, J.J.; Ritzel, D.V. A Semi-Empirical Equation for the Viscosity of Air; Suffield Technical Note No. 454; Defence Research Establishment: Suffield, AB, Canada, 1979.

61. Crabtree, L.F.; Dommett, R.L.; Woodley, J.G. Estimation of Heat Transfer to Flat Plates, Cones and Blunt Bodies; Aeronautical Research Council Reports and Memoranda, R. \& M. No. 3637; Her Mmjesty's Stationery Office: London, UK, 1970.

62. Akin, D.L. Entry Aerothermodynamics, Slides from. 2012 NASA Thermal and Fluids Analysis Workshop. Available online: https:/ /tfaws.nasa.gov/TFAWS12/Proceedings/Aerothermodynamics\%20Course.pdf (accessed on 15 August 2019).

63. Lide, D.R. (Ed.) CRC Handbook of Chemistry and Physics, 84th ed.; CRC Press: Boca Raton, FL, USA, 2003.

64. Johnson, R.; Killpatrick, D.H. Evaluation of Dispersion Strengthened Nickel-Base Alloy Heat Shields for Space Shuttle Application; National Aeronautics and Space Adminstration: Washington, DC, USA, 1976.

65. Haugsrud, R. On the high-temperature oxidation of nickel. Corros. Sci. 2003, 45, 211-235. [CrossRef]

66. Finfrock, C.C.; Greene, G.A. Oxidation of Inconel 718 in Air at Temperatures from 973 K to 1620 K; Energy Sciences and Technology Department, Brookhaven National Laboratory: Upton, NY, USA, 2000.

67. Astle, M.J.; Weast, R.C. CRC Handbook of Chemistry and Physics, 63rd ed.; CRC Press: Boca Raton, FL, USA, 1982.

68. “0.02" Nickel 625 Sheet. OnlineMetals.com. 2019. Available online: https://www.onlinemetals.com (accessed on 19 September 2019).

69. Scruggs, D.M. Modified Chromium for Unprotected Structures. ARS J. 1961, 31, 1527-1533. [CrossRef]

70. Hallström, S.; Halvarsson, M.; Höglund, L.; Jonsson, T.; Ågren, J. High temperature oxidation of chromium: Kinetic modeling and microstructural investigation. Solid State Ionics 2013, 240, 41-50. [CrossRef]

71. Dickinson, C.D.; Seigle, L.L. Experimental Study of Factors Controlling the Effectiveness of High-Temperature Protective Coatings for Tungsten; Technical Documentary Report No. ASD-TDR-63-774; Defense Documentation Center for Scientific and Technical Information Cameron Station: Alexandria, VA, USA, 1964.

72. Ceramfiber, Ceramic Fiber Blanket by Ceramafiber. Amazon. 2019. Available online: https://www.amazon. com/ceramafiber-Ceramic-Fiber-Blanket-Insulation/dp/B0771QNP3G/ (accessed on 19 September 2019).

73. Product Data Book, Thermal Ceramics Is a Business of Morgan Advanced Materials. 2018. Available online: http:/ / www.morganthermalceramics.com/ (accessed on 6 September 2019). 
74. CeramicFiberOnline, Ceramic Fiber Paper Zirconia Grade, CeramicFiberOnline. 2019. Available online: https: / / www.ceramicfiberonline.com/product/ceramic-fiber-paper-552-108240125/ (accessed on 1 September 2019).

75. Jenkins, D.R.; Launius, R.D. Coming Home: Reentry and Recovery from Space; US Government Printing Office: Washington, DC, USA, 2011.

(C) 2020 by the author. Licensee MDPI, Basel, Switzerland. This article is an open access article distributed under the terms and conditions of the Creative Commons Attribution (CC BY) license (http:// creativecommons.org/licenses/by/4.0/). 